Document downloaded from:

http://hdl.handle.net/10251/103785

This paper must be cited as:

Desantes J.M.; José M García-Oliver; Novella Rosa, R.; Pérez-Sánchez, EJ. (2017). Application of an unsteady flamelet model in a RANS framework for spray A simulation. Applied Thermal Engineering. 117:50-64. doi:/10.1016/j.applthermaleng.2017.01.101

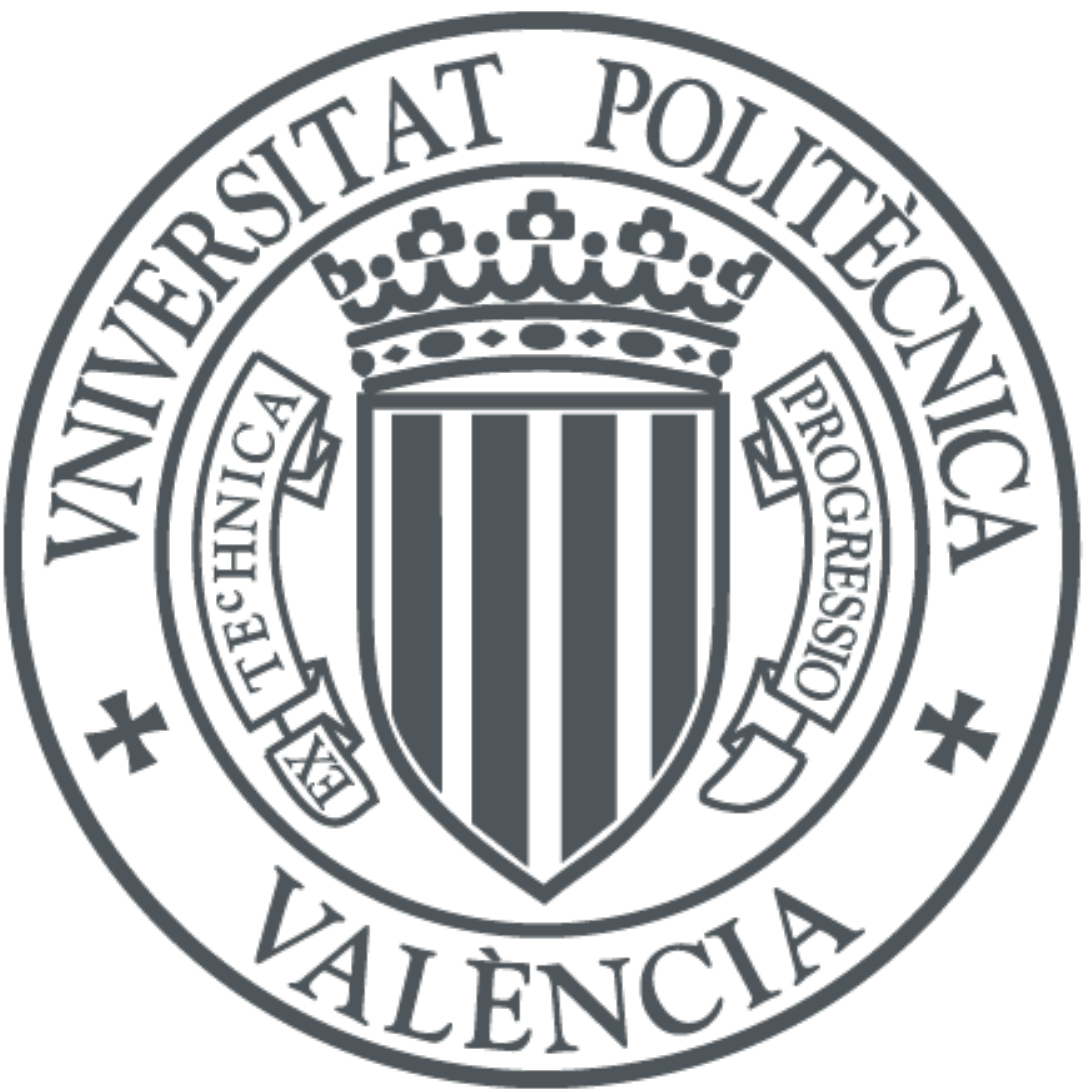

The final publication is available at

http://dx.doi.org/10.1016/j.applthermaleng.2017.01.101

Copyright Elsevier

Additional Information 


\title{
Application of an unsteady flamelet model in a RANS framework for spray A simulation
}

\author{
J.M. Desantes, J.M. García-Oliver * R. Novella, and E.J. Pérez-Sánchez \\ CMT - Motores Térmicos, Universitat Politècnica de València \\ Edificio 6D, Camino de Vera s/n, 46022, Valencia, Spain \\ Tel. (0034) 963877650 / Fax (0034) 963877659
}

\begin{abstract}
In the present investigation the Spray A reference configuration defined in the framework of the Engine Combustion Network (ECN) has been modeled by means of an Unsteady Flamelet Model (USFM) including detailed parametric studies to evaluate the impact of ambient temperature, oxygen concentration and density. The study focuses on the analysis of the spray ignition delay, the flame lift-off length and the internal structure of the spray and flame according to the experimental information nowadays available for validating the results provided by the model.

Promising results are obtained for the nominal case and also for the parametric variations (temperature, oxygen...) in terms of liquid and vapor penetration, ignition delay (ID) and lift-off length (LOL). The model permits to predict the ID and the LOL which constitute two parameters of key importance for describing the characteristics of transient reacting sprays. Valuable insight on the details of the combustion process is obtained from the analysis of formaldehyde $\left(\mathrm{CH}_{2} \mathrm{O}\right)$, acetylene $\left(\mathrm{C}_{2} \mathrm{H}_{2}\right)$ and hydroxide $(\mathrm{OH})$ species in spatial coordinates and also in the so-called $\phi-T$ maps. Important differences arise in the inner structure of the flame in the quasi-steady regime, which is closely linked to soot formation, when varying the ambient boundary conditions. Additionally, the auto-ignition process is investigated in order to describe in detail the spatial onset and propagation of combustion. Results confirm the impact of the ambient conditions on the regions of the spray where start of combustion takes place, so the relation between the local scalar dissipation rate and mixture fraction variance is also discussed. This investigation provides an insight of the potential of the USFM combustion model to describe the physical and chemical processes involved in transient spray combustion.
\end{abstract}

${ }^{*}$ Corresponding author. E-mail: jgarciao@mot.upv.es 


\section{Keywords}

Combustion modeling, Engine Combustion Network, Spray A, Unsteady flamelet model, Auto-ignition

\section{Introduction}

During the last decades the increasing interest for improving combustion efficiency and decreasing pollutant emissions in diesel engines highlighted the needs of achieving a better understanding of the combustion process in transient sprays. However, due to the great variety of physical and chemical phenomena involved in these complex problems, with so different time and length scales, this is still a challenging topic. Experimental measurements have historically provided the cornerstones of the knowledge on basic processes that occur in diesel sprays. In addition to experimental data and more recently, Computational Fluid Dynamic (CFD) modeling has arisen as a very powerful tool that enables to investigate the inner structure of diesel sprays providing valuable knowledge that has lead to important progress in applied combustion science $([1,[2,[3])$.

Nevertheless, practical reasons sometimes impose strong hypotheses in the models in order to maintain a limited computational time that introduce additional uncertainties along the modeling workflow. In this sense both experimental and modeling activities are complementary and permit together to figure out the different aspects of the problem.

Following this approach, the Engine Combustion Network (ECN) (4]) provides a large database with high-quality experimental results generated at different international institutions $([5,6,7])$. One of the most valuable aspects of these experiments is that they are carried out under well-defined and controlled conditions, discarding a great amount of the inherent uncertainties related to measurements in industrial devices.

Together with the experimental database great modeling effort has been devoted to evaluate and improve the CFD combustion models by performing numerical experiments. These simulations have the ability to reproduce the internal processes of the spray, providing in general good qualitative and in some cases also quantitative results in terms of ignition delay (ID) and lift-off length (LOL) compared to the available experimental data ([, 9]). Additionally, the structure of the flame in terms of temperature, species and velocity fields has been a matter of interest in the modeling area and has encouraged the comparison of different models for providing suitable descriptions of the flame ([10, 11, 12]). 
In the last times attention has been focused on the so-called spray A where n-dodecane is used as a diesel surrogate fuel. Boundary conditions span over a wide range and special emphasis is devoted to those conditions related to low temperatures and moderate EGR corresponding to the framework of combustion in modern diesel engines. Such boundary conditions are challenging for modeling because of the strong turbulence-chemistry interaction (TCI) ([10]).

Global parameters of the reactive flow such as ignition delay (ID) and lift-off length (LOL) together with the spray penetration and liquid length are indicators of major relevance that are systematically analyzed in reactive spray simulations in order to determine the predictive performance of models. Together with these parameters optical techniques, such as planar laser-induced fluorescence (PLIF) and high-speed schlieren imaging, permit to describe the transient evolution of the reacting spray and its internal structure by tracing the species spatial position during the combustion onset and development ([13]). This provides new data for validating qualitatively the models in terms of their capability for reproducing the temporalspatial reacting spray structure.

Several institutions have experimentally characterized spray A with different facilities that can be classified in constant-volume pre-burn (CVP) combustion vessels and constant-pressure flow $(\mathrm{CPF})$ rigs ([6]). A CPF experimental facility is available at CMT-Motores Térmicos and the database generated in this facility is used along this research $([\underline{6}, 14,15])$.

Although spray A boundary conditions permit to investigate the internal flame structure and check the capability of the models, diesel engine simulations encompass a great variety of conditions and it is a requirement for the models to have the ability to yield acceptable results in these conditions with limited computational times. Between the different models that provide good results for industrial configurations the flamelet model in conjunction with tabulated chemistry has demonstrated to be one of the most powerful for premixed and nonpremixed turbulent combustion modeling ([16, 17, 18, 19]). In such models flamelet look-up tables, which save the chemistry evolution in laminar flames, are generated previous to the CFD computation reducing drastically the computational time. Based on the satisfactory results provided for diesel engines by the Unsteady Flamelet Model (USFM) ([20, 21]) together with Intrinsic Low Dimensional Manifolds (ILDM), a similar approach has been adopted for this work.

In particular, the Approximated Diffusion Flamelet (ADF) model ([22]) proposed some years ago for managing complex chemical mechanisms keeping a low computational cost has 
been used in this work to generate the laminar flamelet manifolds. The ADF model has been extensively validated including non-premixed laboratory flames ([23, 24]) and diesel engine simulations $([25,26])$, providing satisfactory results in all cases. The major advantage of the ADF model is then its suitability for generating the laminar flamelet manifolds in a very short time (few hours) even using complex chemical mechanisms.

As a main objective, this work investigates the spray A auto-ignition and combustion processes for the reference boundary conditions and also for parametric variations of ambient temperature, oxygen concentration and density. This study includes the description of the trends followed by the ID and LOL and additionally the analysis of the most relevant species fields in spatial coordinates and also in the intrinsic non-premixed combustion coordinates defined by the local equivalence ratio $(\phi)$ and temperature $(T)$, which define the so-called $\phi-T$ maps widely used in spray combustion analysis. The modeling results will be compared with the available experimental data to evaluate the performance of the model. Thus, the paper starts by the methodology section, where the different spray and combustion models and the parametric studies carried out are described. The final model setup is defined and validated by comparing with experiments in non-reacting and reacting conditions. The next results and discussion section include the analysis of the global parameters, such as ID and LOL, followed by a dedicated discussion about the auto-ignition process and finally the reacting spray structure is described in detail. To close the paper the last section summarizes the main conclusions of the present investigation.

\section{Methodology}

\subsection{Description of the model}

The model was implemented in the open tool-box OpenFoam environment. A RANS (Reynolds Averaged Navier-Stokes) approach was used and cylindrical symmetry was supposed, i.e. the solution was obtained on a plane that corresponds to a meridian cut of a cylinder with a radius and a height equal to $54 \mathrm{~mm}$ and $108 \mathrm{~mm}$, respectively. The mesh was structured with a constant cell size of 0.25 (radial direction) $\times 0.5 \mathrm{~mm}$ (axial direction) in the whole domain as suggested in [27].

A standard $k-\epsilon$ RANS turbulence model was selected adjusting $C_{\epsilon_{1}}=1.52$ in order to correct the well-known round jet spreading overestimation of $k-\epsilon$ type models ([28]), 
which provides good results in spray simulations ([29]). The other constants were kept at their standard values $\left(C_{\mu}=0.09, C_{\epsilon_{2}}=1.92, C_{\epsilon_{3}}=-0.33, \sigma_{k}=1, \sigma_{\epsilon}=1.3\right)$.

The DDM (discrete droplet method) modeling approach has been adopted in this research work. The DDM comprises different sub-models that define the evolution of the spray liquid phase and its interaction with the gaseous carrier phase. In this work the atomization and breakup processes are described by modeling the Kelvin-Helmholtz/Rayleigh-Taylor instabilities. The values of the constants for the breakup and atomization models adopted for this work are $B_{0}=0.61, B_{1}=40, C_{\tau}=1, C B U=3$ as suggested in [27]. Additionally, the Ranz-Marshall model was selected for droplet evaporation with a multiplicative factor of 0.6 and exponents 0.5 and 1/3 for Reynolds and Prandtl numbers, respectively. Neither collisions nor coalescence models were included for the simulation of the spray. The number of parcels was chosen to be $5.4 * 10^{7}$ parcels/s.

The chemical mechanism used in this work to describe the dodecane chemistry corresponds to the Narayanaswamy et al. mechanism with 255 species and 2289 reactions ([30]).

In the following the combustion model is briefly described. The theoretical background of the model is based on locally describing the turbulent non-premixed combustion as an ensemble of laminar diffusion flames called flamelets. This hypothesis is suitable for flows with high Damköhler numbers $(D a>>1)$ as those found in diesel engine or gas turbine combustion systems. Only gradients in the normal direction to the flame surface are retained leading to the diffusion flamelet (DF) model ([31, 32]).

The DF model solves, for all the $N_{k}$ species considered in the chemical mechanism, the 1-D diffusion flamelet equation that reads $([32])$

$$
\frac{\partial Y_{k}}{\partial t}=\frac{\chi}{2} \frac{\partial^{2} Y_{k}}{\partial Z^{2}}+\dot{\omega}_{k} \quad k=1, \ldots, N_{k}
$$

where $Z$ is the mixture fraction, which ranges from 0 to the saturation mixture fraction $\left(Z_{\text {sat }}\right)$, and $\chi$ is the scalar dissipation rate defined as $\chi=2 D|\nabla Z|^{2}$. In general, a steady profile for the scalar dissipation rate is adopted leading to the following expression ([32])

$$
\chi(a, Z)=\frac{a}{\pi} Z_{\text {sat }}^{2} \exp \left[-2\left(\operatorname{erfc} c^{-1}\left(2 Z / Z_{\text {sat }}\right)\right)^{2}\right]
$$

where the strain rate is termed as $a$. It is useful to split $a$ and $Z$ dependencies in equation (2) 
and reparametrise $a$ with the stoichiometric scalar dissipation rate, $\chi_{s t}$, leading to

$$
\chi\left(\chi_{s t}, Z\right)=\chi_{s t} \frac{F(Z)}{F\left(Z_{s t}\right)}
$$

where $Z_{s t}$ is the stoichiometric mixture fraction.

The chemical source term $\dot{\omega}_{k}$ that appears on the right hand side of equation (1) is calculated from the ODE system defined by the chemical mechanism.

Solving the complete system of equations for complex mechanisms that involve hundreds of species and thousands of reactions becomes not feasible in a reasonable time specially when performing engine simulations that require the calculation of sets of flamelets with boundary conditions spanning over wide ranges of values.

The ADF model ([22]) adopted in this work was proposed with the aim of decreasing drastically the computational cost for the generation of the flamelet manifolds required by the USFM combustion models applied to industrial devices simulations. In this model equation (1) is only solved for the progress variable $Y_{c}$, which is defined as a linear combination of species mass fractions. Mathematically, the key condition for the progress variable is that its definition has to assure a strictly monotonous evolution with time during the auto-ignition of the homogeneous reactors (HRs). Conventionally, $Y_{c}$ is chosen to be increasing with time. The chemical source term of the progress variable transport equation is calculated from a set of HRs whose thermochemical evolution from fresh to burnt gases for a given mixture fraction is described by the progress variable value. For these calculations the HR database has been calculated at constant pressure and adiabatic conditions. The transport equation for $Y_{c}$ reads

$$
\frac{\partial Y_{c}}{\partial t}=\frac{\chi(a, Z)}{2} \frac{\partial^{2} Y_{c}}{\partial Z^{2}}+\dot{\omega}_{c}^{H R}\left(Z, Y_{c}\right)
$$

For the sake of clarity explicit dependencies have been written. This decoupling between chemical $\left(\dot{\omega}_{c}^{H R}\left(Z, Y_{c}\right)\right)$ and convection-diffusion $\left(\frac{\chi(a, Z)}{2} \frac{\partial^{2} Y_{c}}{\partial Z^{2}}\right)$ terms permits to manage complex chemical mechanisms in reduced amounts of time. The chemical source term $\dot{\omega}_{c}^{H R}$ in equation (4) is always positive by virtue of the strictly increasing relationship between $Y_{c}$ and time. Note that when reducing the strain rate to zero the DF, ADF and HRs solutions tend to converge (no diffusion in Z-space). A comparison between DF and ADF models can be found in [22, 33].

In this work, the progress variable $Y_{c}$ is defined as $Y_{c}=Y_{C O}+Y_{C_{2}}$, which is a widely used definition $([22,34])$. For practical reasons it is also interesting to define the normalized progress 
variable $c$, which ranges between 0 and 1,as

$$
c=\frac{Y_{c}-Y_{c}^{\text {inert }}}{Y_{c}^{\text {equil }}-Y_{c}^{\text {inert }}}
$$

where $Y_{c}^{\text {inert }}$ and $Y_{c}^{\text {equil }}$ are the corresponding $Y_{c}$ values at the inert and equilibrium conditions of the HR, respectively.

For the following calculations the initial values for $\mathrm{CO}$ and $\mathrm{CO}_{2}$ are zero so equation (5) becomes

$$
c=\frac{Y_{c}}{Y_{c}^{e q u i l}}
$$

A flamelet database is generated where reactive variables $\psi$ lay on a surface (low dimensional manifold $)$ that depends on $\left(\tau, Z, \chi_{s t}\right)$ input parameters, so $\psi=\psi\left(\tau, Z, \chi_{s t}\right)$ where $\tau$ corresponds to the flamelet time. Following [35] only flamelets that belong to the auto-ignition range, i.e. the $\chi_{s t}$ interval where flamelets can evolve from inert to steady conditions, are considered in the flamelet database.

The initial conditions (temperature and species mass fractions) for the calculation of the HRs are given by the adiabatic mixture between air and fuel. For the present study around 160 mixture fractions (depending on the value of $Z_{\text {sat }}$ ) have been computed between 0 and $Z_{\text {sat }}$ with a finer mesh resolution in the stoichiometric and slightly rich mixtures $(\Delta Z=0.001$ for these range of mixture fractions). Because this work focuses on the analysis of the capabilities of the combustion model and also in order to reduce numerical uncertainties a fine mesh is imposed in the progress variable direction with 504 points with higher resolution for low $c$ values. Both $Z$ and $c$ grids define a regular mesh. The HRs database contains the $\dot{\omega}_{c}^{H R}(Z, c)$ as well as the species and temperature evolutions from the HRs calculations.

For solving equation (4), first, the steady solutions of the flamelet equation are computed by means of a Newton-Raphson algorithm with a second order discretization for the diffusion term. Once the possible states of the flamelet are known (bounded by the inert and the steady profiles for the progress variable) the transient regime is calculated with an implicit numerical scheme with second order discretization for the diffusion term and first order for the time derivative. When solving steady and transient equations all variables are retrieved by means of linear interpolations from the HRs database.

Turbulent fluctuations are accounted for by means of presumed probability density functions 
(pdf). Statistical independence is assumed for probability density functions leading to

$$
\widetilde{\psi}\left(\tau, \widetilde{Z}, S, \overline{\chi_{s t}}, \sigma\right)=\int_{0}^{\infty} \int_{0}^{Z_{s a t}} \psi\left(\tau, Z, \chi_{s t}\right) P_{Z}(Z, \widetilde{Z}, S) P_{\chi_{s t}}\left(\chi_{s t}, \overline{\chi_{s t}}, \sigma\right) d Z d \chi_{s t}
$$

In equation (7) a delta Dirac function is assumed for the progress variable pdf. Mixture fraction fluctuations are defined by the average mixture fraction $(\widetilde{Z})$ and its variance $\left(\widetilde{Z^{\prime \prime 2}}\right)$ that for convenience is parametrized with the segregation factor $S$. A beta function is assumed for $P_{Z}$ ([31]), while a log-normal function with average equal to $\overline{\chi_{s t}}$ and fixed variance $\sigma^{2}$ is assumed for $P_{\chi_{s t}}$. In this work $\sigma^{2}=2$ has been imposed for all calculations ([36]). Additionally, a reparametrization of the input parameters is introduced to switch from the flamelet time $\tau$ to the progress variable $\widetilde{Y}_{c}$ getting $\widetilde{\psi}=\widetilde{\psi}\left(\widetilde{Z}, S, \overline{\chi_{s t}}, \widetilde{Y}_{c}\right)$, where the dependence with $\sigma$ is omitted because it takes a fixed value.

Expression (7) can be difficult to evaluate because of the asymptotes that can appear for the beta function or other numerical difficulties so for accelerating the convergence process when iterating the integral is split in different intervals. Normally the integrand of equation (7) shows strong variations in located intervals so it is useful to integrate these intervals, which have few points and require a lot of iterations, separately.

In this work, for the final tabulation around 32 values have been considered for $\widetilde{Z}$ (depending on the $Z_{\text {sat }}$ value) with a finer discretization for slightly rich mixtures, 17 values for $S$ spanning from 0 to 0.3 and around 35 values have been saved in the $\overline{\chi_{s t}}$ direction (depending on the extension of the auto-ignition range). Finally, 51 values following a parabolic distribution, which enables high resolution for low progress variable values that are critical for not distorting the ignition delay, have been stored in the progress variable direction.

Additionally, the $\chi$ profile is integrated too

$$
\begin{aligned}
\tilde{\chi} & =\int_{0}^{\infty} \int_{0}^{Z_{s a t}} \chi_{s t} \frac{F(Z)}{F\left(Z_{s t}\right)} P_{Z}(Z, \widetilde{Z}, S) P_{\chi_{s t}}\left(\chi_{s t}, \overline{\chi_{s t}}, \sigma\right) d Z d \chi_{s t} \\
& =\overline{\chi_{s t}} \int_{0}^{Z_{s a t}} \frac{F(Z)}{F\left(Z_{s t}\right)} P_{Z}(Z, \widetilde{Z}, S) d Z=\overline{\chi_{s t}} J(\widetilde{Z}, S)
\end{aligned}
$$

where function $J(\widetilde{Z}, S)$ links $\widetilde{\chi}$ with $\overline{\chi_{s t}}$.

Species chemical source terms for species transport equations are retrieved from the turbulent database with the set of parameters $\left(\widetilde{Z}, S, \overline{\chi_{s t}}, \widetilde{Y}_{c}\right)$. Transport equations for the mixture 
fraction and its variance are solved and the value of $\tilde{\chi}$ is algebraically obtained from the equation

$$
\tilde{\chi}=C_{\chi} \frac{\varepsilon}{k} \widetilde{Z^{\prime \prime 2}}
$$

where $C_{\chi}$ is a model constant to be calibrated as described in next section, while $k$ and $\epsilon$ are the turbulent kinetic energy and its dissipation rate, respectively. Then, $\overline{\chi_{s t}}$ is obtained from $\tilde{\chi}$ by means of $J$. A more detailed description of this USFM combustion model and its coupling with the CFD solver can be found in [37].

This approach can be extended for solving compressible reactive flows with evolving boundary conditions, such as in diesel engines, retaining the TCI with reduced computational times ([34]). In the case of the spray A the well-defined and constant boundary conditions permit to reduce the input parameters to those explained previously.

\subsection{Parametric study description}

The boundary conditions of the parametric study correspond to those experimentally measured at CMT-Motores Térmicos in the CPF facility $([\underline{6}])$, where the ambient gas thermochemical conditions are controlled by supplying an oxygen and nitrogen mixture compressed and preheated before entering into the open combustion chamber in which the fuel is injected.

The nominal case is defined by setting the ambient conditions at $T=900 \mathrm{~K}, X_{\mathrm{O}_{2}}=0.15$ and $\rho=22.8 \mathrm{~kg} / \mathrm{m}^{3}$ and four parametric studies were considered. The first two vary the temperature from $T=750 \mathrm{~K}$ to $900 \mathrm{~K}$ for $X_{\mathrm{O}_{2}}=0.15$ and 0.21 keeping the density at the nominal level. The third simulates the effect of different dilution levels (for instance by introducing EGR, exhaust gas recirculation, in a diesel engine), so the oxygen concentration ranges from $X_{\mathrm{O}_{2}}=0.13$ to 0.21 with temperature and density at the nominal levels. Finally, the fourth spans in the density (ambient pressure $p_{a m b}$ ) direction with values ranging from $\rho=7.6$ to $22.8 \mathrm{~kg} / \mathrm{m}^{3}$. All the studies have been carried out with a constant injection pressure, $p_{i n j}$, equal to $150 M P a$ and a long injection rate has been imposed $(>4 m s)$, shown in figure1, for enabling the study of the quasi-steady state. The injection rate was obtained from the virtual injection rate generator that can be found in [38] and the profile is accepted in the ECN community for calculations. The different boundary conditions and the stoichiometric mixture fraction $Z_{s t}$ are summarized in table 1 .

The injector has a nominal diameter of $90 \mu \mathrm{m}$, with nozzle code 210675 (44]), and discharge 
coefficient equal to 0.98. The fuel temperature is assumed constant at $363 \mathrm{~K}$.

Table 1: Definition of the spray A parametric studies.

\begin{tabular}{cccccc}
\hline$X_{O 2}$ & $T_{a m b}(K)$ & $\rho_{a m b}\left(\mathrm{~kg} / \mathrm{m}^{3}\right)$ & $p_{a m b}(\mathrm{MPa})$ & $p_{i n j}(\mathrm{MPa})$ & $Z_{s t}$ \\
\hline \hline 0.13 & 900 & 22.8 & 5.98 & 150 & 0.040 \\
\hline 0.15 & 750 & 22.8 & 4.97 & 150 & 0.046 \\
\hline 0.15 & 800 & 22.8 & 5.3 & 150 & 0.046 \\
\hline 0.15 & 850 & 22.8 & 5.63 & 150 & 0.046 \\
\hline 0.15 & 900 & 7.6 & 1.99 & 150 & 0.046 \\
\hline 0.15 & 900 & 15.2 & 3.98 & 150 & 0.046 \\
\hline 0.15 & 900 & 22.8 & 5.96 & 150 & 0.046 \\
\hline 0.21 & 750 & 22.8 & 4.93 & 150 & 0.063 \\
\hline 0.21 & 800 & 22.8 & 5.26 & 150 & 0.063 \\
\hline 0.21 & 900 & 22.8 & 5.91 & 150 & 0.063 \\
\hline
\end{tabular}

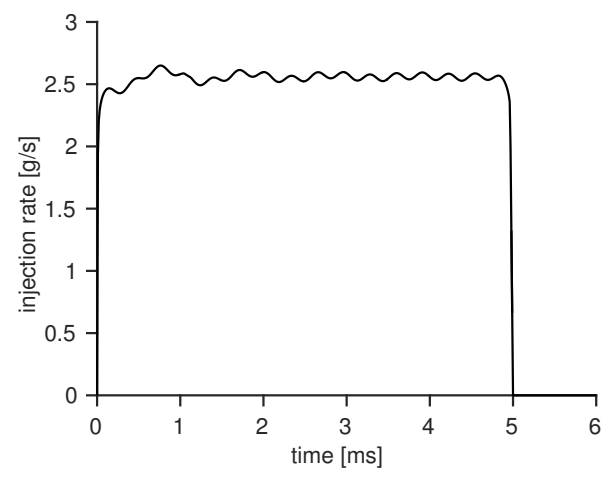

Figure 1: Injection rate as a function of time.

\section{Results and discussion}

\subsection{Set-up of the model}

A detailed comparison between the modeling and the experimental results for both the inert and the reactive cases for the nominal case is shown in this section. For modeling results the liquid length is defined as the distance to the nozzle where $95 \%$ of the injected liquid is found and the vapor penetration as the maximum distance from the nozzle outlet to where mixture fraction is 0.001 .

Figure 2 shows liquid lengths and vapor penetrations, where shadowed regions delimit the uncertainty of the measurement. It is observed how the liquid length $(\sim 9.7 \mathrm{~mm}$ for the experiment) is well-captured by the model and the difference between its value for the inert and the reactive cases is negligible due to the existing spatial isolation between the evaporation and the combustion regions. 
The modeled vapor penetration for the inert case falls well inside the experimental uncertainty until the very last instants. In the reactive case it is slightly overestimated as a result of the difficulties for correctly modeling the thermal expansion of the jet when switching from inert to reacting conditions, but nonetheless the model provides the high quality results required to proceed with further analysis.

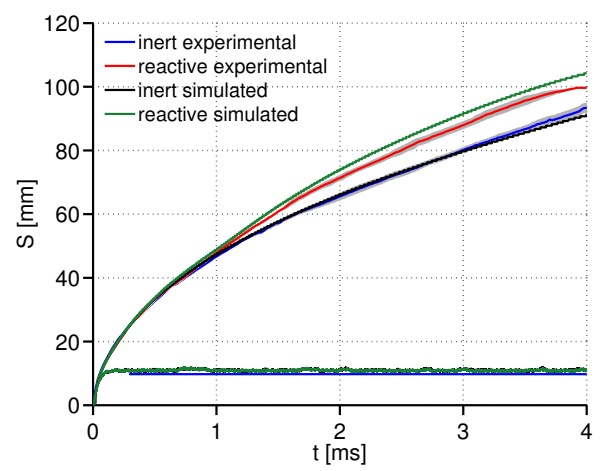

Figure 2: Vapor penetration and liquid length for inert experimental (blue), reactive experimental (red), inert simulated (black) and reactive simulated (green) conditions. For experiments measurements uncertainty is delimited with shadows.

A much deeper insight is provided by comparing the average and rms (root mean square) mixture fraction profiles and also the normalized axial velocity profile on the spray centerline, together with average and rms mixture fraction radial profiles at different axial positions. In general, very few measurements are available for the reactive case so the comparison mainly focuses on the inert case. Because average and rms mixture fractions as well as velocity fields were measured with different nozzles, 210677 for mixture fraction ([4, 39]) and nozzle 210678 for velocity profiles $(4,40,41])$, coordinates have been normalized with the equivalent diameter defined as $d_{e q}=d_{0} \sqrt{\rho_{f} / \rho_{a}}$ where $d_{0}$ is the nozzle diameter and $\rho_{f}, \rho_{a}$ are the fuel and air densities, respectively.

Figure 3 top left corresponds to the $\widetilde{Z}$ and the normalized axial velocity $\left(\widetilde{U} / \widetilde{U_{0}}\right)$ on the centerline for the inert and reactive cases. Focusing on the mixture fraction profiles it is evident how the simulation shows an excellent correspondence with the measured profile in inert conditions. Additionally, due to the acceleration of the flow caused by the thermal expansion, the mixture fraction value at a given axial position downstream the LOL is expected to be higher for the reactive case and the model captures this trend correctly. The normalized velocity profiles also show excellent agreement for both inert and reactive cases, so the model provides similar quality performance than that observed for the mixture fraction.

In addition to the centerline mixture fraction profiles two cuts at 50 and $90 d_{e q}$ (that ap- 

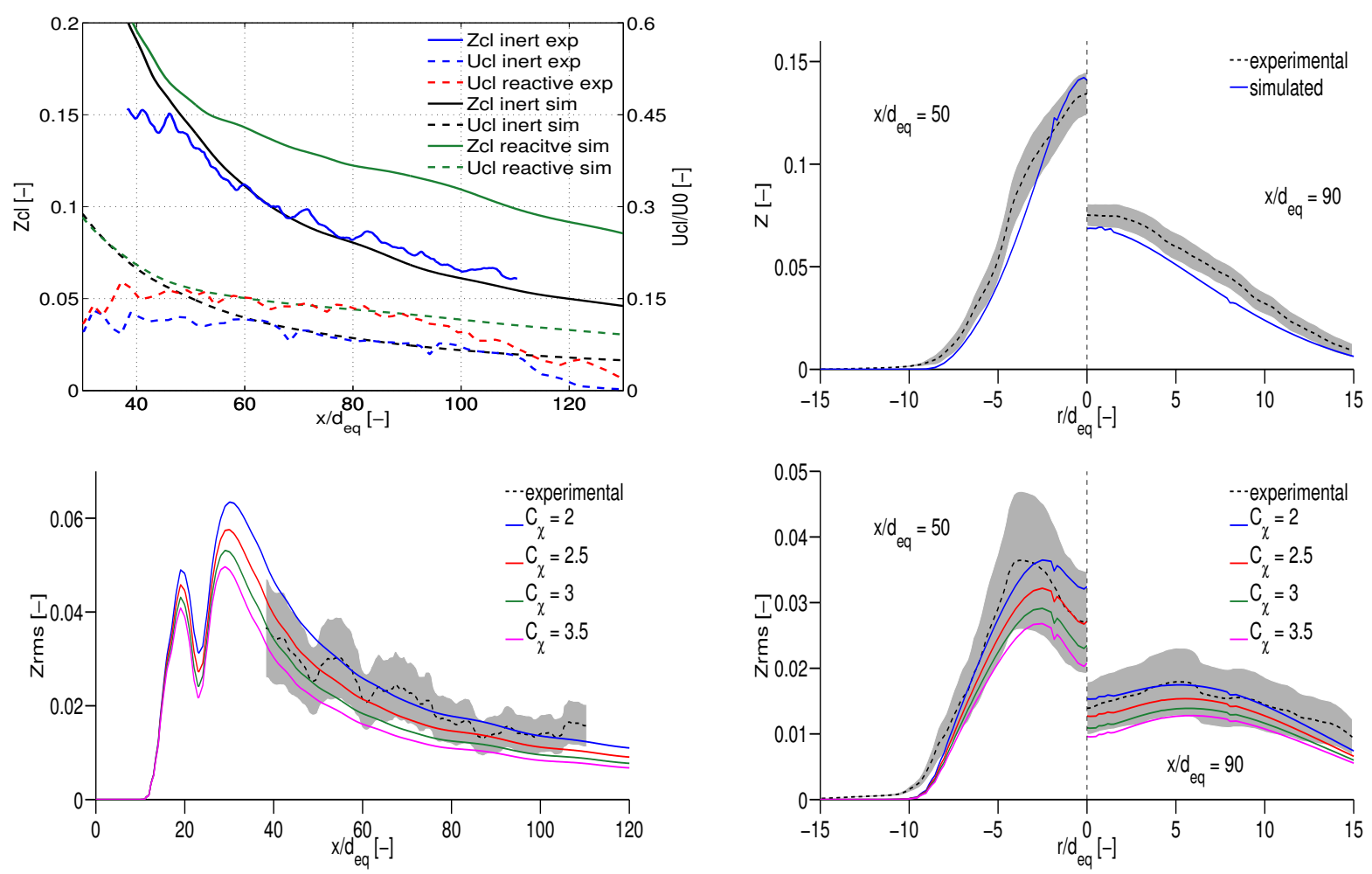

Figure 3: Comparison between simulated and experimental mixture formation results at very advanced instants. Top left: $\widetilde{Z}$ and normalized $\widetilde{U}$ on the centerline. Top right: $\widetilde{Z}$ radial profiles at 50 and $90 d_{e q}$. Bottom left: $Z_{r m s}$ on the centerline. Bottom right: $Z_{r m s}$ radial profiles at 50 and $90 d_{e q}$. Experimental uncertainties are shown with shadowed regions while simulated profiles with different $C_{\chi}$ are included in rms plots.

proximately correspond to 25 and $45 \mathrm{~mm}$, respectively) for the inert case are included in Figure 3 top right. The radial distance is normalized with the equivalent diameter and the experimental uncertainties are delimited by shadowed zones. By virtue of the imposed cylindrical symmetry only one half of the spray is represented. Modeling results show a good agreement with measurements as expected after the previous discussion, although the simulation slightly underestimates the measured profiles.

The rms mixture fraction $\left(Z_{r m s}\right)$ profiles for the inert case are represented in Figure 3 bottom left and bottom right. Figure 3 bottom left shows $Z_{r m s}$ on the centerline and Figure 3 bottom right shows $Z_{r m s}$ radial cuts at axial distances equal to 50 and $90 d_{e q}$. The experimental measurements together with their uncertainties are depicted as well as different simulated cases with values of $C_{\chi}=2,2.5,3,3.5$ (see equation $(9)$ ). $Z_{r m s}$ is used to adjust the $C_{\chi}$ constant, which has a great influence for determining $\tilde{\chi}$ value and indirectly the $\overline{\chi_{s t}}$ flamelet manifold input parameter. From these results it is observed that $C_{\chi}=2$ provides the best fitting so this value will be adopted for the following reactive calculations.

Thus the model provides very good results for spray mixture formation in inert and reactive 
conditions in terms of mean field values and also mixture fraction fluctuations if calibrating properly the $C_{\chi}(=2)$ constant.

\subsection{Analysis of the reactive spray macro-parameters}

This section is dedicated to the analysis of the trends followed by the two most relevant macroparameters used to characterize transient reacting sprays, the ignition delay and the lift-off length.

Experimentally ID and LOL are both determined by chemiluminescence, ID as the time spent to reach a $50 \%$ of the high-temperature chemiluminescence level and LOL as the location where a $50 \%$ of the leveling-off value of $O H^{*}$ chemiluminescence is observed ([4]).

For modeling results the ID is defined as the time spent from start of injection (SOI) until the maximum rise of maximum Favre-averaged temperature takes place ([4]). However, some discussion about the most suitable definitions for the modeling LOL results and their influence can be found in the literature ([42]). Promoted by this lack of consensus several definitions for the LOL have been evaluated in this work. More specifically, two criteria defined as the minimum axial distance to the nozzle where $2 \%$ and $14 \%$ of the maximum value of $\widetilde{Y_{O H}}$ in the domain is reached as well as a third criterion defined as the minimum axial distance to the nozzle where the ambient temperature plus $400 K$ is reached ([4, 43, 44]).

Tables 2 and 3 gather the ID and LOL values for the modeled cases corresponding to the parametric studies together with the experimental results and their related uncertainty ([14]).

Figures 4, 5, 6 and 7 show the ID and the LOL with different criteria for temperature, oxygen and density parametric variations, where the uncertainties of the measured values are represented by error bars. In the temperature parametric variations none of the simulated LOL values for the $T_{a m b}=750 \mathrm{~K}$ cases stabilized during the long injection $(>4 \mathrm{~ms})$ and therefore no value is assigned.

With regards to both temperature parametric variations the trends followed by both parameters are well-captured, however, ID is overestimated specially for low temperatures. In the case of $X_{\mathrm{O}_{2}}=0.15$, LOL value shows excellent agreement with the $14 \% \widetilde{Y_{\mathrm{OH}}}$ max criterion. It was observed that the $2 \%{\widetilde{Y_{O H}}}^{\text {max }}$ criterion was related to very low temperature increments above the ambient temperature (around $\sim 50 K$ ) suggesting that this percentage value is too low for being representative. The $T_{a m b}+400 K$ criterion, unlike the previous low temperature criteria, corresponds to very high temperatures for tracking the LOL and in general it provides 
Table 2: ID values for experiments (including uncertainty) and simulations for the parametric spray A variations.

\begin{tabular}{ccccc}
\hline$X_{O 2}$ & $T_{a m b}(K)$ & $\rho_{a m b}\left(\mathrm{~kg} / \mathrm{m}^{3}\right)$ & $I D_{\exp } \pm I D_{u n c}(\mathrm{~ms})$ & $I D_{\text {sim }}(\mathrm{ms})$ \\
\hline \hline 0.13 & 900 & 22.8 & $0.529 \pm 0.039$ & 0.6094 \\
\hline 0.15 & 750 & 22.8 & $2.342 \pm 0.073$ & 3.2309 \\
\hline 0.15 & 800 & 22.8 & $0.994 \pm 0.035$ & 1.6218 \\
\hline 0.15 & 850 & 22.8 & $0.666 \pm 0.032$ & 0.8549 \\
\hline 0.15 & 900 & 7.6 & $1.938 \pm 0.129$ & 1.3908 \\
\hline 0.15 & 900 & 15.2 & $0.701 \pm 0.04$ & 0.739 \\
\hline 0.15 & 900 & 22.8 & $0.435 \pm 0.036$ & 0.5533 \\
\hline 0.21 & 750 & 22.8 & $2.172 \pm 0.045$ & 3.0005 \\
\hline 0.21 & 800 & 22.8 & $0.853 \pm 0.05$ & 1.3715 \\
\hline 0.21 & 900 & 22.8 & $0.316 \pm 0.031$ & 0.4715 \\
\hline
\end{tabular}

Table 3: LOL values for experiments (including uncertainty) and simulations for the parametric spray A variations.

too high values as it is shown in all cases. When passing to a higher oxygen concentration, $X_{\mathrm{O}_{2}}=0.21$, the three criteria slightly overestimate LOL although the relation between them is preserved $\left(L O L_{2 \%}<L O L_{14 \%}<L O L_{400 K}\right)$.
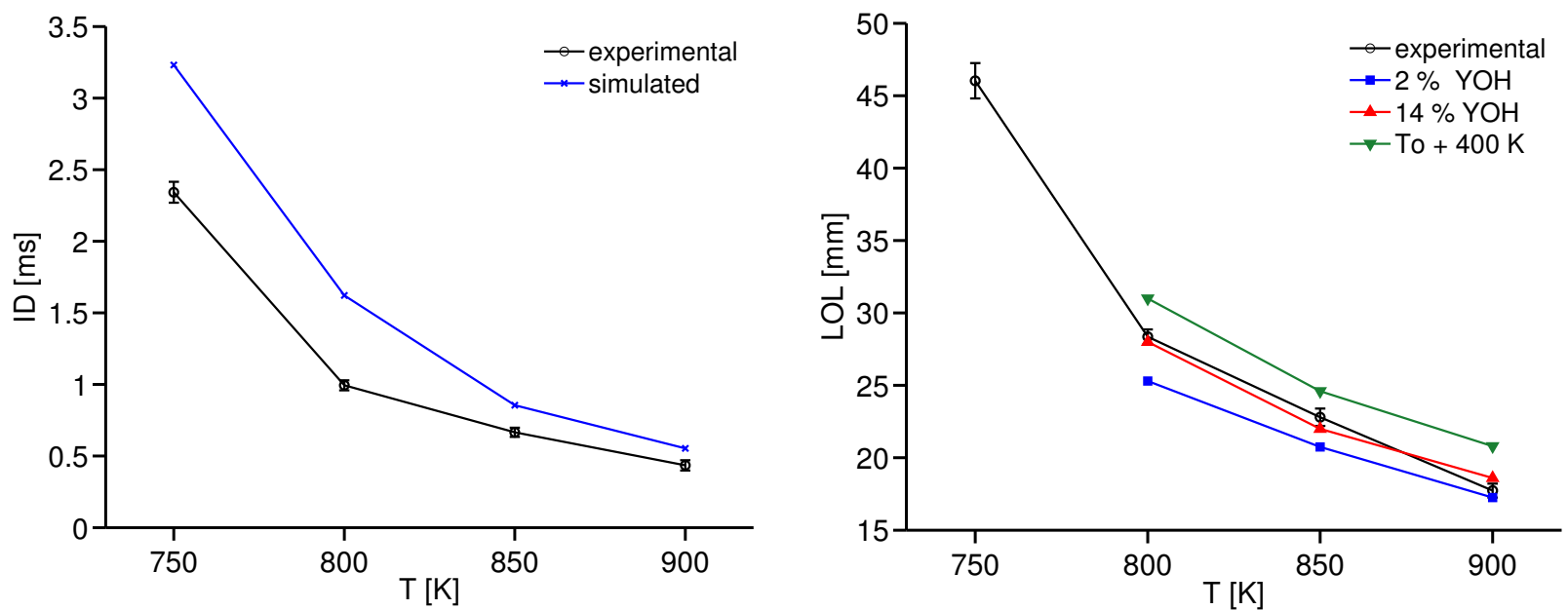

Figure 4: ID and LOL with different criteria for the parametric temperature variation with $X_{O_{2}}=0.15$ and $\rho=22.8 \mathrm{~kg} / \mathrm{m}^{3}$. Left: ID for experimental (black) and modeled (blue). Right: LOL for experimental (black), modeled with $2 \%{\widetilde{Y_{O H}}}^{m a x}$ (blue), $14 \%{\widetilde{Y_{O H}}}_{\max }$ (red) and $T_{a m b}+400 K$ (green). In both figures error bars indicate the experimental uncertainty. 

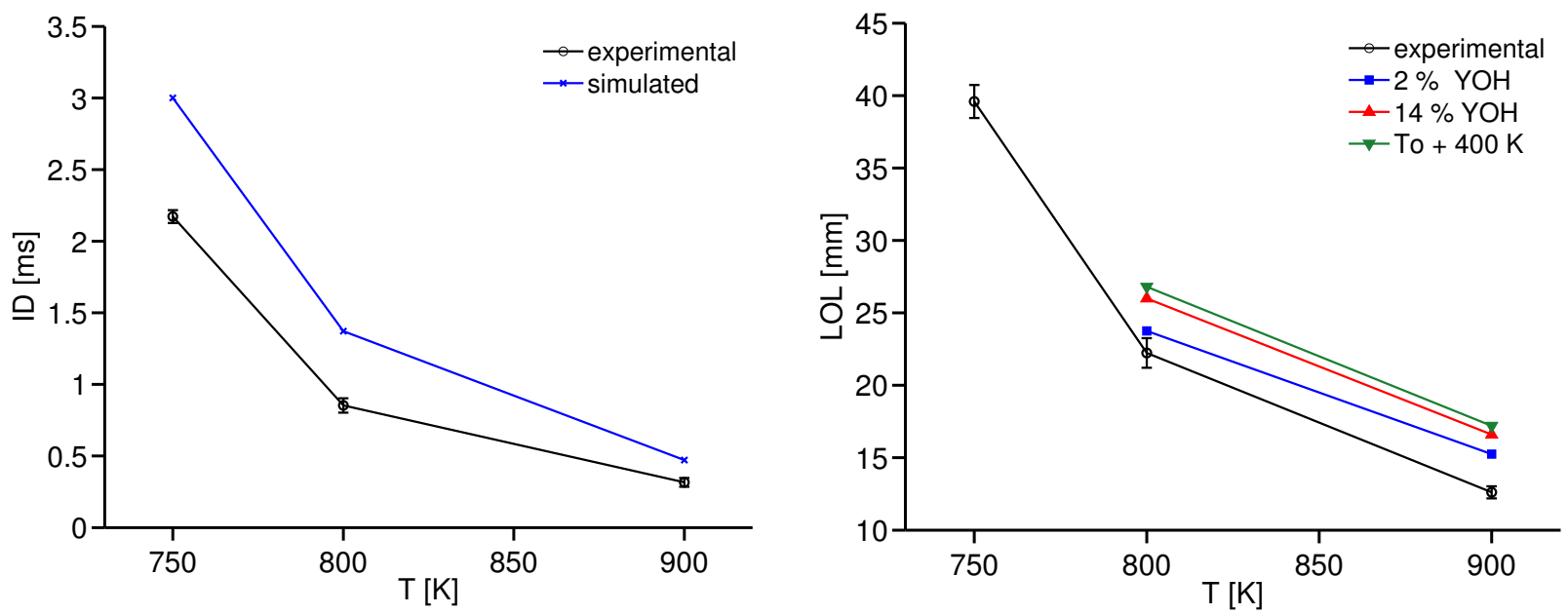

Figure 5: ID and LOL with different criteria for the parametric temperature variation with $X_{\mathrm{O}_{2}}=0.21$ and $\rho=22.8 \mathrm{~kg} / \mathrm{m}^{3}$. Left: ID for experimental (black) and modeled (blue). Right: LOL for experimental (black), modeled with $2 \%{\widetilde{Y_{O H}}}^{m a x}$ (blue), $14 \%{\widetilde{Y_{O H}}}_{\max }$ (red) and $T_{a m b}+400 K$ (green). In both figures error bars indicate the experimental uncertainty.
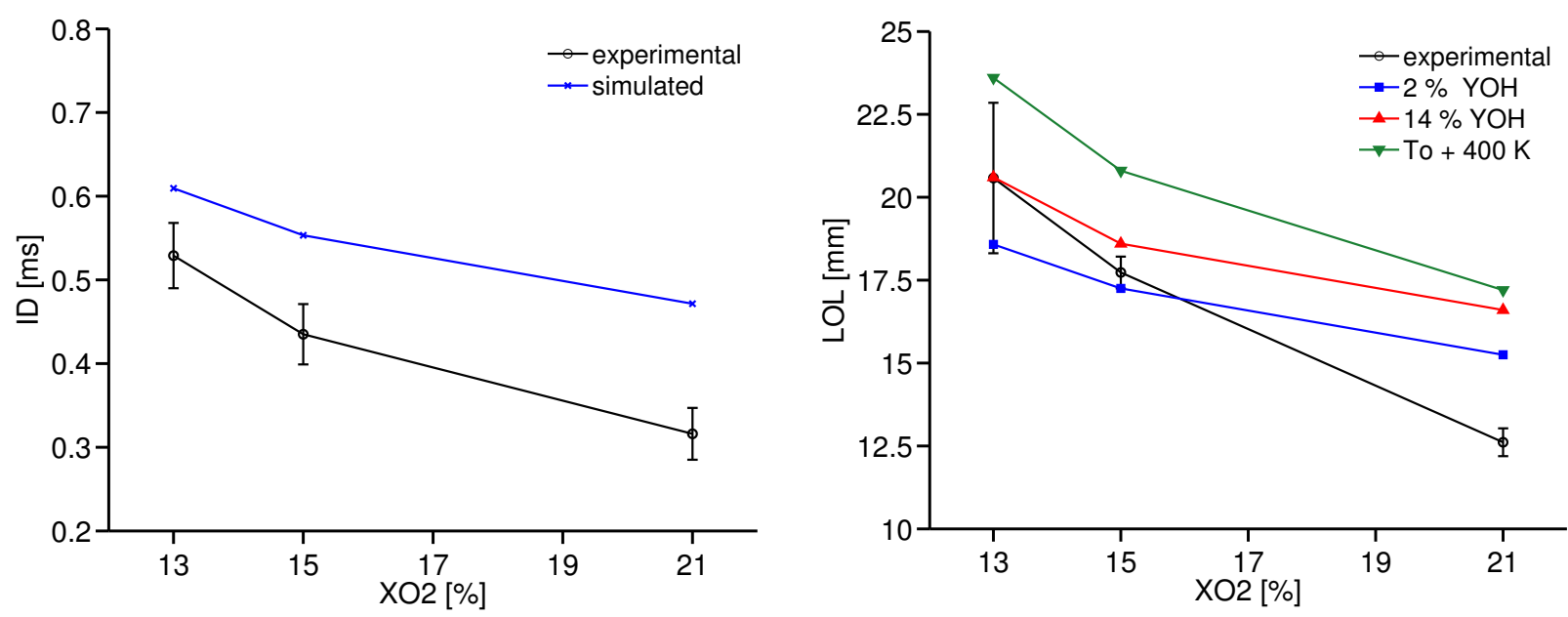

Figure 6: ID and LOL with different criteria for the parametric oxygen variation with $T_{a m b}=900 \mathrm{~K}$ and $\rho=22.8 \mathrm{~kg} / \mathrm{m}^{3}$. Left: ID for experimental (black) and modeled (blue). Right: LOL for experimental (black), modeled with $2 \% \widetilde{Y_{O H}}$ max (blue), $14 \% \widehat{Y}_{O H} \max$ (red) and $T_{a m b}+400 K$ (green). In both figures error bars indicate the experimental uncertainty. 

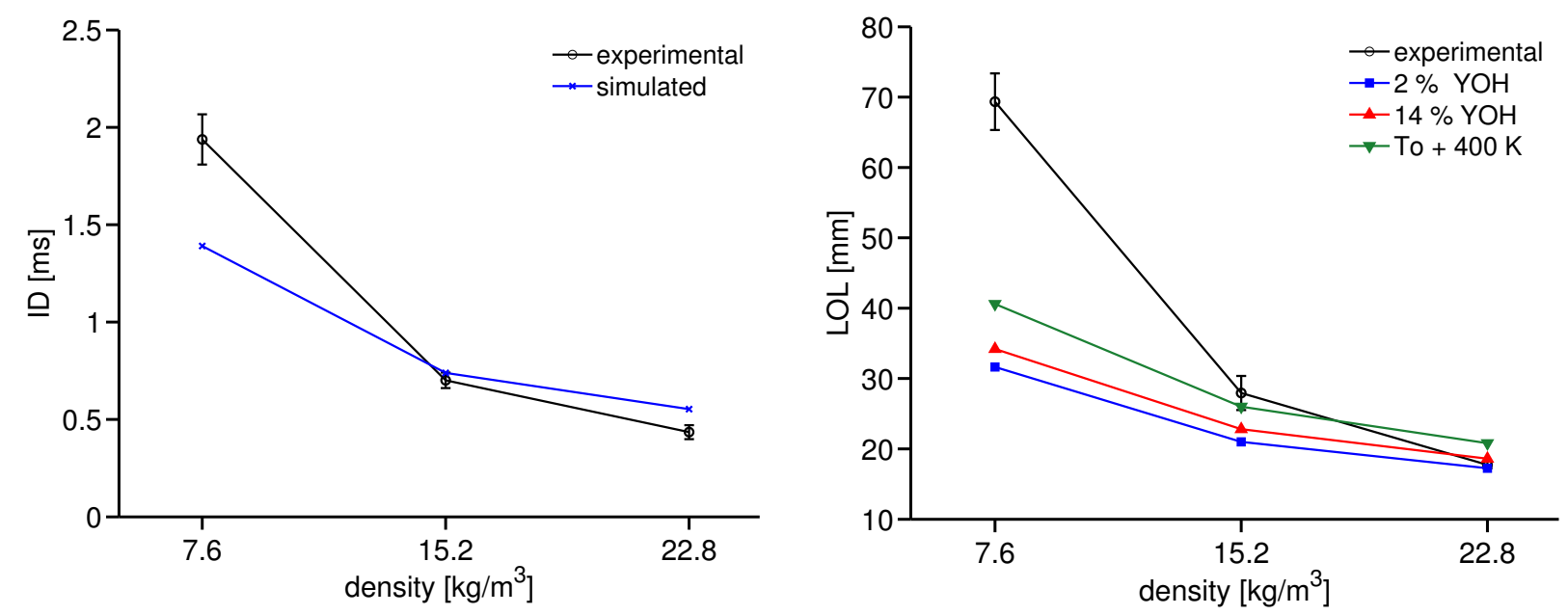

Figure 7: ID and LOL with different criteria for the parametric density variation with $T_{a m b}=900 \mathrm{~K}$ and $X_{O_{2}}=0.15$. Left: ID for experimental (black) and modeled (blue). Right: LOL for experimental (black), modeled with $2 \% \widetilde{Y_{O H}} \widetilde{m a x}_{\text {(blue), }}$ $14 \%{\widetilde{Y_{O H}}}^{\max }$ (red) and $T_{a m b}+400 \mathrm{~K}$ (green). In both figures error bars indicate the experimental uncertainty.

Analyzing the oxygen parametric variation the model correctly predicts the trends although the sensitivity is slightly lower than that observed in the experiments. The ID is overestimated in the three cases but the prediction is clearly better at low-intermediate oxygen concentration. Concerning the LOL, when increasing oxygen concentration the slope of the modeled curve decreases overestimating the corresponding LOL experimental value independently from the criteria. Nevertheless, for low oxygen concentrations the LOL value given by both criteria based on ${\widetilde{Y_{O H}}}^{m a x}$ is within the interval defined by the experimental uncertainty.

Finally, for the density parametric variation acceptable results are achieved for the medium and high density cases for both ID and LOL values. Nevertheless, for the low density case the ID and the LOL are underestimated as reported in the literature (9]).

Additionally, valuable information is obtained when establishing the relationship between the ID and the LOL values for the whole set of points that define the parametric study. This is shown in figure 8 that includes all the points of the parametric matrix. It is well-known that, in general, shorter ID produces shorter LOL $([45,46])$ in correspondence with experimental and modeling results shown in figure 8. It seems that a linear relationship with positive slope exist between each group of points (experimental and simulated with different criteria) specially for points with $I D<1 \mathrm{~ms}$. Nevertheless, for points with high ID the linear relationship vanishes and the dispersion of the points indicates that no apparent correlation can be established (the relation between ID and LOL not only depends on these variables but on the ambient conditions too). The fact that this dispersion exists in all the represented cases (experimental 
Table 4: Linear regression coefficients defined as $L O L(m m)=b_{0}+b_{1} * I D(m s)$ for experimental and simulated cases following

different LOL criteria. stated that, in general, the existing relationship between ID and LOL for the different boundary conditions points out that the LOL is deeply linked with the auto-ignition phenomenon as the stabilization flame mechanism $([45,47])$.

\begin{tabular}{ccc}
\hline Case & $b_{0}$ & $b_{1}$ \\
\hline \hline Experimental & 10.4 & 18.6 \\
\hline $2 \%{\widetilde{Y_{O H}}}_{\text {max }}$ & 12.2 & 10 \\
\hline $14 \%{\widetilde{Y_{O H}}}^{m a x}$ & 13 & 11.1 \\
\hline$T_{a m b}+400 K$ & 14.4 & 12.6 \\
\hline
\end{tabular}

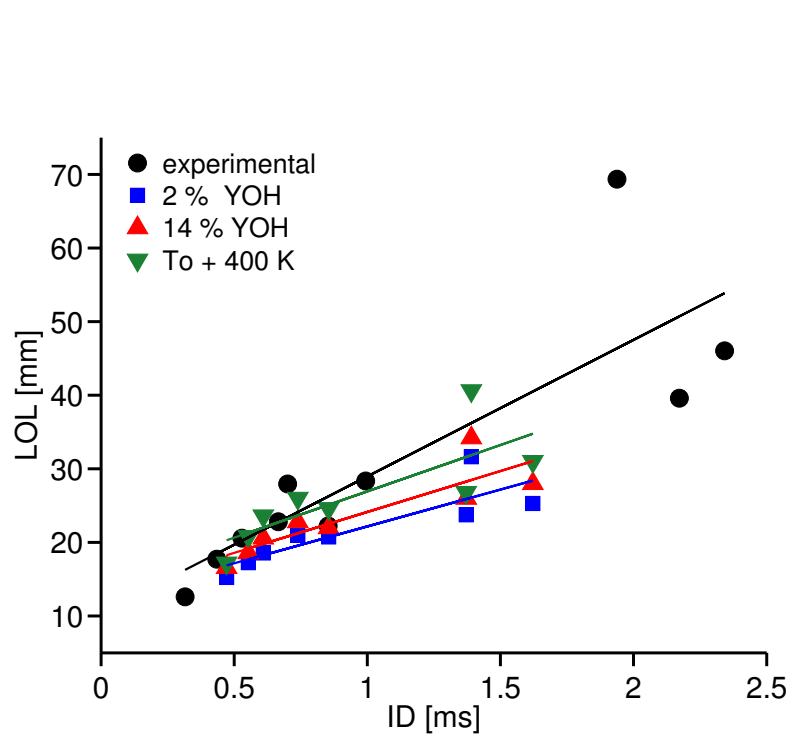

Figure 8: Relationship between ID and LOL for experimental (black circle) and simulated values with different LOL criteria: $2 \%{\widetilde{Y_{O H}}}^{\max }$ (blue squares), $14 \%{\widetilde{Y_{O H}}}^{\max }$ (red upward-pointing triangles) and $T_{a m b}+400 \mathrm{~K}$ (green downward-pointing triangles). With the corresponding color linear regressions are included for each cloud of points.

and simulated) seems to suggest that it is not only attributable to error measurements or uncertainties of other nature but a real existing dispersion is related to high ID (alternatively LOL) values. Table 4 includes the defining coefficients of the linear fit for the different cases. It is interesting to observe that all simulated criteria even providing different (ID, LOL) pairs follow a very similar behaviour what it is denoted by the parallelism of the lines. Summarizing, it can be

\subsection{Analysis of the auto-ignition process}

This section provides first a description of the auto-ignition process of the mixture by means of the mixture fraction and temperature spatial fields for different ambient conditions and later a discussion of the ignition in terms of the mixture fraction fluctuations and the scalar dissipation rate. The aim of this section is to study how this transient phenomenon spatially occurs and the relationship with the key characteristics of the turbulent flow field. 
For that purpose three representative points belonging to the parametric variations have been selected showing their ignition sequence process in figures 9, 10 and 11. In general, for better visibility the length of the axis for the distinct cases does not coincide but the corresponding values of the contour lines of the equivalence ratio and temperature fields have been kept the same for all cases. For the fuel-air equivalence ratio (plotted in blue) the chosen values are 1, 1.5 and 2 while for the temperature (red) the values are 1200, 1500, 1800, 2000 and $2250 \mathrm{~K}$. Due to the transient nature of the problem it is obvious how in these figures the assigned temperatures are not always reached and consequently the corresponding lines are not plotted. The position of the lines is not explicitly indicated but the structure of the flame makes it clear.

The auto-ignition process for the nominal case is first shown in figure 9 . As it can be observed the ignition kernels (for intermediate temperatures) appear first at rich mixtures, $\widetilde{\phi} \sim 2$, and when advancing in time the highest temperature is found at leaner mixtures, what will be pointed out later in the $\phi-T$ maps shown in next section ([48]). Due to the low related ID when ignition starts the spatial location for ignition is limited to the radial region at the head of the spray that is left between contour lines corresponding to $\widetilde{\phi}=1$ and 2 . The heat release and consequent density decrease provokes an instability in the flow that is reflected in a radial expansion of the spray ([15]). The enthalpy diffusion together with chemical reactions permit that higher $\widetilde{\phi}$ values reach intermediate temperatures spreading the zone of temperatures $>1200 \mathrm{~K}$ to a wider region that includes part of the axis when time advances. Nevertheless, ignition kernels were first observed in a radial position as it is experimentally confirmed ([13]).
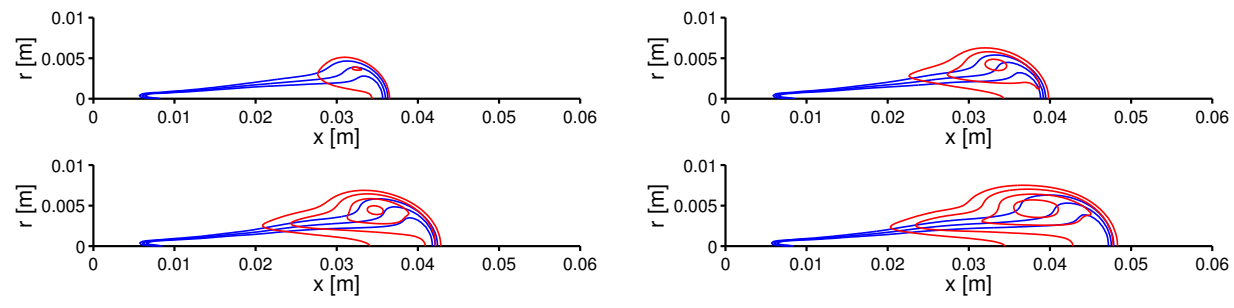

Figure 9: Ignition process for $T_{a m b}=900 \mathrm{~K}, X_{\mathrm{O}_{2}}=0.15$ and $\rho=22.8 \mathrm{~kg} / \mathrm{m}^{3}$ in spatial coordinates for instants 600 (top left), 700 (top right), 800 (bottom left) and $1000 \mu \mathrm{s}$ (bottom right). Fuel-air equivalence ratio contour lines for 1, 1.5 and 2 (blue) and temperature contour lines for 1200, 1500, 1800 and $2000 K$ (red) are shown.

Figure 10 shows the auto-ignition process for the $T_{a m b}=900 K, X_{O_{2}}=0.21$ and $\rho=$ $22.8 \mathrm{~kg} / \mathrm{m}^{3}$ case, which is more reactive than the reference case due to the higher oxygen concentration. Qualitatively, the process is very similar to the nominal case basically changing the maximum temperature reached in the domain and the characteristic chemical time. Again in 
this case ignition kernels appear at very early time instants when the contour lines $\widetilde{\phi}=1$ and 2 are still very close. In this way, ignition kernels are observed in a radial position and the enthalpy diffusion together with chemical reactions rapidly spread the zone with intermediate and high temperatures in a very similar way to that indicated in the nominal case.
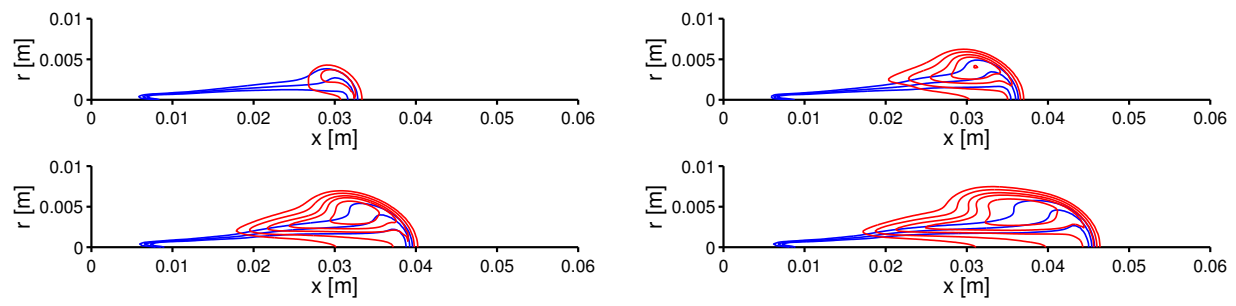

Figure 10: Ignition process for $T_{a m b}=900 \mathrm{~K}, X_{\mathrm{O}_{2}}=0.21$ and $\rho=22.8 \mathrm{~kg} / \mathrm{m}^{3}$ in spatial coordinates for instants 500 (top left), 600 (top right), 700 (bottom left) and $900 \mu s$ (bottom right). Fuel-air equivalence ratio contour lines for 1, 1.5 and 2 (blue) and temperature contour lines for 1200, 1500, 1800, 2000 and $2250 K$ (red) are shown.

Nevertheless, the igniting sequence for the case $T_{a m b}=800 K, X_{O_{2}}=0.15$ and $\rho=$ $22.8 \mathrm{~kg} / \mathrm{m}^{3}$, that is gathered in figure 11 , is quite different from those shown previously due to the lower reactivity as a consequence of the reduction of the ambient temperature. In this case, the time evolution of the mixture fraction field is similar to that corresponding to the nominal case (at least during the first stages of the ignition), nonetheless, the characteristic chemical time has notably increased by the reduction of the ambient temperature. As a consequence, when the first steps of ignition at intermediate-high temperatures occur the mixture field is stabilized for $\widetilde{\phi}$ contour lines of 1.5 and 2 . Ignition kernels originate in the head of the spray spreading in a zone that cuts the centerline in a region whose $\widetilde{\phi}$ values range between 1 and 1.5. The heat release and consequent acceleration of the flow tend to displace high temperature regions to further radial positions as it is observed for instants like $2500 \mu s$.
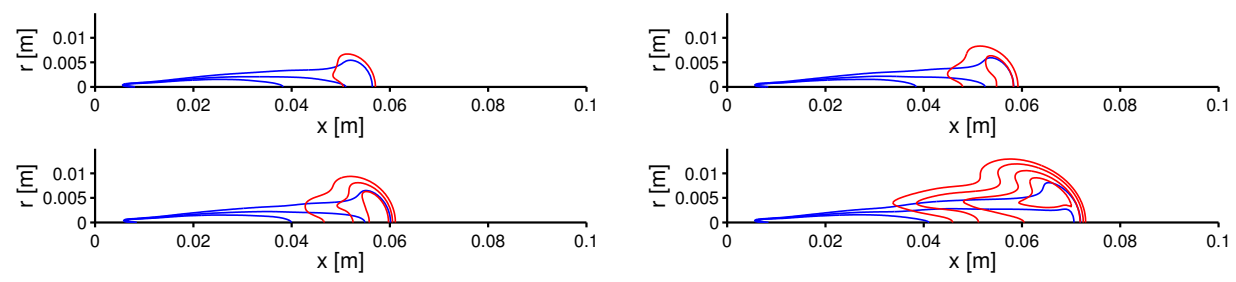

Figure 11: Ignition process for $T_{a m b}=800 \mathrm{~K}, X_{O_{2}}=0.15$ and $\rho=22.8 \mathrm{~kg} / \mathrm{m}^{3}$ in spatial coordinates for instants 1500 (top left), 1600 (top right), 1700 (bottom left) and $2500 \mu \mathrm{s}$ (bottom right). Fuel-air equivalence ratio contour lines for 1, 1.5 and 2 (blue) and temperature contour lines for 1200, 1500, 1800 and $2000 K$ (red) are shown.

In summary, it is concluded that the spatial location of the ignition depends on the boundary conditions which determine characteristic mixing and chemical times and the relationship between them establishes the spatial onset process. 
Completing the description of the ignition onset by means of the analysis of the spatial mixture fraction and temperature fields an insightful depiction is provided by the start of combustion in terms of parameters that account for turbulence. For this purpose figures 12 and 13 show the mixture fraction variance, $\widetilde{Z^{\prime \prime 2}}$, and the normalized progress variable, $\widetilde{c}$, as a function of the stoichiometric scalar dissipation rate, $\overline{\chi_{s t}}$, during the first steps of the ignition along specific mixture fraction contour lines. More specifically, two cases of those shown previously, selected as paradigmatic of different ignition processes, that correspond to $800 \mathrm{~K}, X_{\mathrm{O}_{2}}=0.15$, $\rho=22.8 \mathrm{~kg} / \mathrm{m}^{3}$ (low reactivity ignition) and $900 \mathrm{~K}, X_{\mathrm{O}_{2}}=0.21, \rho=22.8 \mathrm{~kg} / \mathrm{m}^{3}$ (high reactivity ignition) are shown. For the sake of brevity, the first one is named low reactivity (LR) case and the second one high reactivity (HR) case.
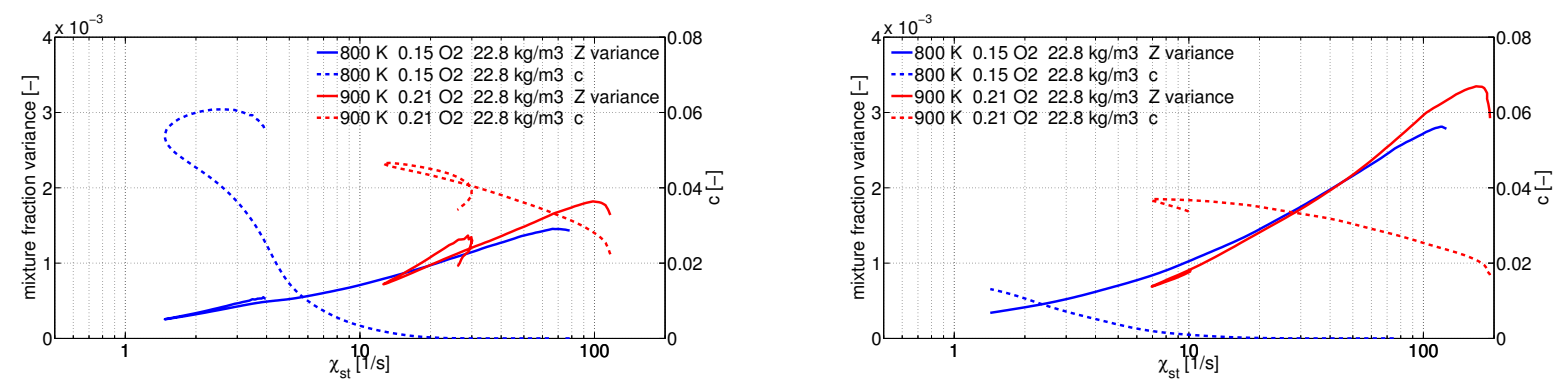

Figure 12: Relationship between $\widetilde{Z^{\prime \prime 2}}$ (solid lines) and $\widetilde{c}$ (dashed lines) with $\overline{\chi_{s t}}$ for LR case (blue) and HR case (red) along contour lines $\widetilde{\phi}=1$ (left) and $\widetilde{\phi}=2$ (right). Selected instant is $1100 \mu s$ for LR case and $400 \mu s$ for HR case. A logarithmic scale is used for $\overline{\chi_{s t}}$.

Figure 12 shows that ignition kernels (low $\widetilde{c}$ values) emerge at low $\widetilde{Z^{\prime \prime 2}}$ values (the maximum $\widetilde{Z^{\prime \prime 2}}$ is $5.5 * 10^{-3}$ in the whole domain) together with low $\overline{\chi_{s t}}$ values. Then, as confirmed in figure 12, the increase of reactivity when passing from LR case to HR case shifts not only the mixture fraction (see figures 10 and 11 but also the $\widetilde{Z^{\prime \prime 2}}$ and the $\overline{\chi_{s t}}$ where ignition starts towards higher values. Consequently, combustion can be sustained at higher $\overline{\chi_{s t}}$ values when the reactivity of the mixture is increased $([49])$.

Figure 13 shows the relation between the aforementioned variables for a more advanced time instant. Compared to the earlier ignition times shown in figure 12 , it arises that higher values of $\overline{\chi_{s t}}$ can be sustained in the combustion process due to the propagation of the combustion to wider regions as it was observed previously in figures 10 and 11 . Nevertheless, a strong fall of the $\widetilde{c}$ variable persists when increasing $\overline{\chi_{s t}}$ values, specially for LR case. As it was pointed out before, an important difference in the $\overline{\chi_{s t}}$ values where combustion is observed is still conserved between LR and HR cases. Note that in the LR case when passing from $\widetilde{\phi}=1$ to $\widetilde{\phi}=2$ the $\widetilde{c}$ value notably decreases what is explained by the displacement of the combustion region to 
leaner mixture fractions in comparison with the HR case (see figure 11 where it is observed that contour line $\widetilde{\phi}=2$ is hardly affected by the high temperature zone in contrast with figure 10 for the HR case). This fact is confirmed by the $\phi-T$ maps included in next section.
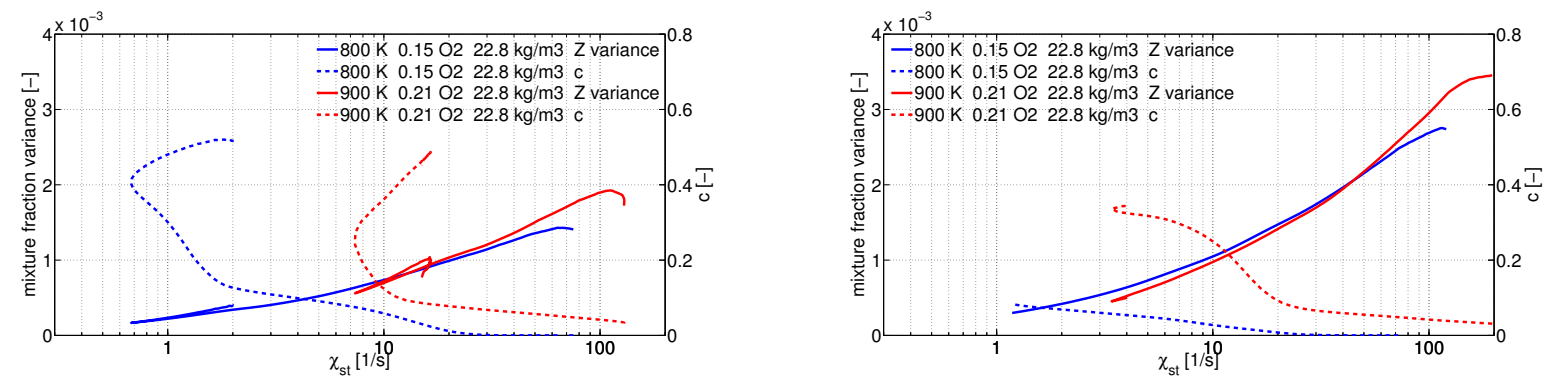

Figure 13: Relationship between $\widetilde{Z^{\prime \prime 2}}$ (solid lines) and $\widetilde{c}$ (dashed lines) with $\overline{\chi_{s t}}$ for LR case (blue) and HR case (red) along contour lines $\widetilde{\phi}=1$ (left) and $\widetilde{\phi}=2$ (right). Selected instant is $1500 \mu \mathrm{s}$ for LR case and $500 \mu \mathrm{s}$ for HR case. A logarithmic scale is used for $\overline{\chi_{s t}}$.

As a final remark the model results evidence the impact of $\widetilde{Z^{\prime \prime 2}}$ and the $\overline{\chi_{s t}}$ on the ignition process, traced by the $\widetilde{c}$ levels, and consequently ignition is not observed in flow regions with high $\overline{\chi_{s t}}$ as discussed in the literature $([49])$.

\subsection{Analysis of the flame structure in quasi-steady regime}

In this section a detailed description of the inner flame structure in physical space and in equivalence ratio-temperature space is carried out focusing on the effects of the ambient conditions. Three different species have been selected as representative tracers of the combustion process and soot formation: formaldehyde $\left(\mathrm{CH}_{2} \mathrm{O}\right)$ as a tracer species of the low-intermediate reaction temperature region, hydroxide $(\mathrm{OH})$ as a tracer of the high temperature reaction zone and acetylene $\left(\mathrm{C}_{2} \mathrm{H}_{2}\right)$ as a soot precursor.

Figure 14 shows a first qualitative comparison carried out for the reference case by means of the $\mathrm{CH}_{2} \mathrm{O}$ and soot precursors mass fraction fields for both experimental ([50]) and simulated cases. Experimental fields were measured with nozzle 210678 so spatial coordinates are normalized with the equivalent diameter. No scale is included in none of the figures due to the difficulty of establishing maxima values for the experimental fields and so values are normalized with the maximum value of the field although experimental results have been saturated for better visibility. In this sense the comparison tends to be only qualitative depicting the spatial regions related to each species. The LOL values for experimental and simulated cases following different criteria are also included with vertical dashed lines. Additionally, in the 
corresponding simulated case the stoichiometric contour line is represented for delimiting the spatial zone where combustion is sustained. Both cases correspond to advanced instants in which quasi-steady regime is ensured in the spray region of interest.

$\mathrm{CH}_{2} \mathrm{O}$ appears both in experiment and simulation in a region close to the LOL, although in the experimental case the $\mathrm{CH}_{2} \mathrm{O}$ field seems to extend upstream of the LOL. Due to the probable interference of PAHs (polycyclic aromatic hydrocarbons) the experimental field is saturated downstream $50 d_{e q}$ for better visibility although the exact starting point of such interference is difficult to define. Furthermore, the extent of the laser sheet is limited to $92 d_{e q}$, approximately. In the case of the modelling results, $\mathrm{CH}_{2} \mathrm{O}$ extends from $35 d_{e q}$ to $65 d_{e q}$, with a small overlap with the $\mathrm{C}_{2} \mathrm{H}_{2}$ field, which extends further downstream. Taking into account the uncertainty in the definition of the extent of the species from the experiments, the main structure of the reactive spray reproduced by modelling in terms of remarkable species is consistent, with a small shift in the downstream direction.
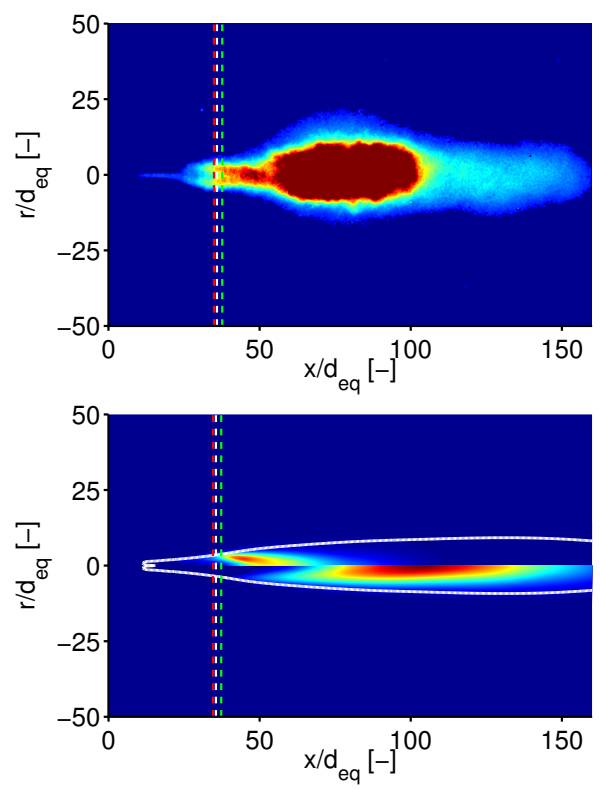

Figure 14: Top figure: experimental $\mathrm{CH}_{2} \mathrm{O}$ PLIF measurements. Bottom figure: on top $\mathrm{CH}_{2} \mathrm{O}$ and on bottom $\mathrm{C}_{2} \mathrm{H}_{2}$ species fields. LOL values are represented with vertical dashed lines: experimental (white), $2 \% \widetilde{Y_{O H}}$ max (red) and $14 \% \widetilde{Y_{O H}}$ max (green). Additionally, for the simulated case the stoichiometric line is shown (solid white).

In the following, a comparison with the spatial fields for the aforementioned species is carried out for different representative parametric variations. Figure 15 shows in matrix format the species $\mathrm{CH}_{2} \mathrm{O}, \mathrm{C}_{2} \mathrm{H}_{2}$ and $\mathrm{OH}$ mass fraction fields for the temperature parametric variation $\left(750,800\right.$ and $900 \mathrm{~K}$ ) with $X_{O_{2}}=0.15$ and density $22.8 \mathrm{~kg} / \mathrm{m}^{3}$. Advanced instants with a similar penetration have been selected and quasi-steady regime in the near-nozzle region is ensured. 
Only simulated cases are included so a quantitative comparison is performed.

As discussed in the previous section the LOL is shortened when increasing the ambient temperature due to the reduction of the chemical time scales. Although there exist some common points in the behavior of all cases, as for instance that the relative position of $\mathrm{CH}_{2} \mathrm{O}$, $\mathrm{C}_{2} \mathrm{H}_{2}$ and $\mathrm{OH}$ is preserved, intrinsic differences in the flame structure arise comparing the different temperature cases. As expected the higher reactivity of the mixture resulting from the increment of the temperature displaces upstream the quasi-steady $\mathrm{CH}_{2} \mathrm{O}$ and $\mathrm{C}_{2} \mathrm{H}_{2}$ fields .

In the case of $750 K$ the reactivity of the mixture is so low that even for the very advanced simulated instant $(4000 \mu s)$ the fields are not still fully developed and the quasi-steady region is not still well established yet. Probably, that is the reason why $\mathrm{CH}_{2} \mathrm{O}$ does not fall in the inner region defined by the stoichiometric contour line.

Additionally, a noticeable fall of the peak value of soot precursors, represented by $\mathrm{C}_{2} \mathrm{H}_{2}$, is observed when decreasing ambient temperature closely linked to an increase of the LOL and the characteristic chemical times as reported in the literature ([51]). In the case of the $750 \mathrm{~K}$ the low peak value of the $\mathrm{C}_{2} \mathrm{H}_{2}$ supports that no noticeable amounts of soot precursors are produced $([50])$

With regards to the $O H$ field, it is observed downstream the LOL and in the vicinity of the stoichiometric contour line where the maximum temperature is reached.
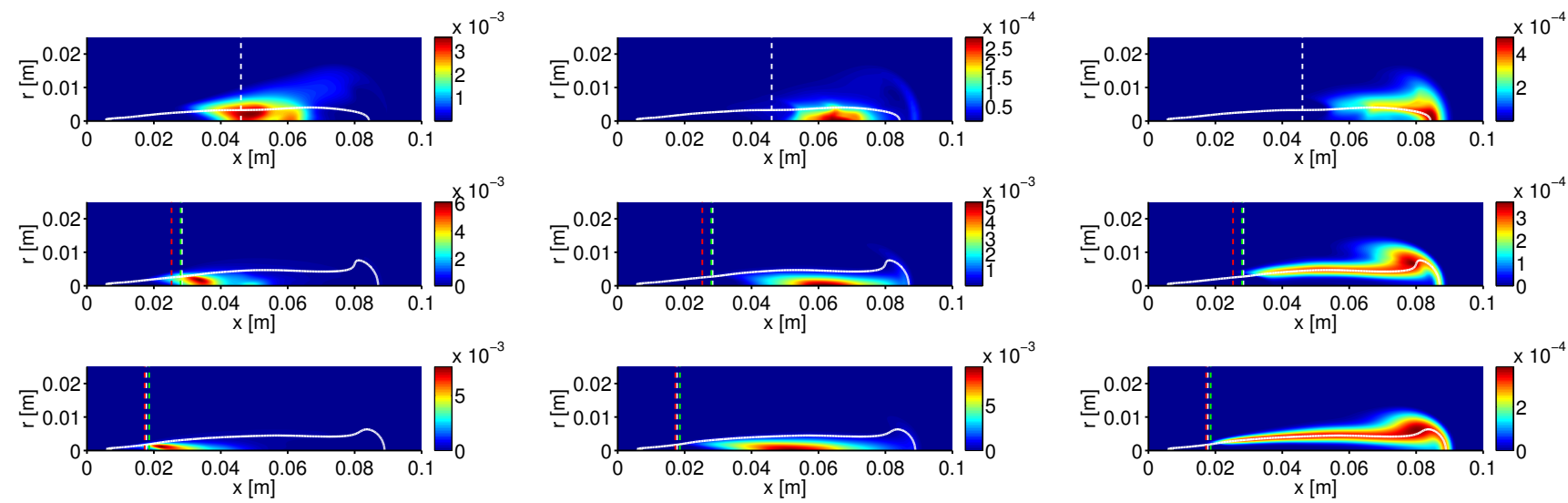

Figure 15: Species mass fractions fields of $\mathrm{CH}_{2} \mathrm{O}$ (left), $\mathrm{C}_{2} \mathrm{H}_{2}$ (center) and $\mathrm{OH}$ (right) for $750 \mathrm{~K}$ (top), $800 \mathrm{~K}$ (middle) and $900 \mathrm{~K}$ (bottom) with $X_{O_{2}}=0.15$ and density $22.8 \mathrm{~kg} / \mathrm{m}^{3}$ in matrix format. LOL values are included with dashed lines: experimental (white), $2 \%{\widetilde{Y_{O H}}}^{\max }$ (red) and $14 \%{\widetilde{Y_{O H}}}^{\max }$ (green). Additionally, the stoichiometric line is shown (solid white).

A deeper description is achieved by representing the flame structure in terms of combustion related parameters such as the equivalence ratio and the temperature to identify the location of the most relevant species. This is carried out by plotting the so-called $\phi-T$ maps, shown 
in figure 16, for the temperature parametric variation $(750,800$ and $900 K)$ with $X_{O_{2}}=0.15$ and $\rho=22.8 \mathrm{~kg} / \mathrm{m}^{3}$ for advanced instants. In order to only include the representative regions where $\mathrm{CH}_{2} \mathrm{O}, \mathrm{C}_{2} \mathrm{H}_{2}$ and $\mathrm{OH}$ can be found only points with $Y_{i}>0.3 \cdot Y_{i}^{\max }$ are shown, where $i$ represents the species $\left(\mathrm{CH}_{2} \mathrm{O}, \mathrm{C}_{2} \mathrm{H}_{2}, \mathrm{OH}\right)$ and superscript max refers to maximum value in the domain.

As it was indirectly observed in the spatial fields the $\mathrm{CH}_{2} \mathrm{O}$ is observed in the region of lowintermediate temperatures, $\mathrm{C}_{2} \mathrm{H}_{2}$ is found at lower equivalence ratios (but still rich mixtures) and higher temperatures and $O H$ dominates the zone of lean, stoichiometric and slightly rich mixtures with very high temperatures. As the reactivity of the mixture increases the chemical time scales are shorter and $\mathrm{CH}_{2} \mathrm{O}$ and $\mathrm{C}_{2} \mathrm{H}_{2}$ appear at higher equivalence ratios. Hence, the stretching of the region of influence of these species reduces the overlap between them. For the three ambient temperatures $O H$ fills a very similar area because it only appears in the vicinity of stoichiometric values where very high local temperatures are reached.

It is interesting to notice how the maximum equivalence ratio in reacting conditions sharply decreases by lowering the ambient temperature, so it ranges from approximately 4 for $T_{a m b}=$ $900 \mathrm{~K}$ to a value around 2 for $T_{a m b}=750 \mathrm{~K}$ as it was alternatively pointed out in figures 9 and 11. This fact is related with experimental observations that show that the decrease of the LOL, due to the variation of the boundary conditions, is linked with an increase of the equivalence ratio at the LOL ([51]).

Additionally, the $\widetilde{T}_{\max }=\widetilde{T}_{\max }(\widetilde{\phi})$ relationship (where $\widetilde{T}_{\max }$ is the maximum Favre averaged temperature in the whole domain) during the ignition process has been included for giving an idea of the ignition evolution. In general, it can be stated that with the increase of the ambient temperature the first stages of the combustion at intermediate temperatures take place at higher equivalence ratios which is a consequence of the reduction of the chemical time scales. Later the process moves to lower equivalence ratios approaching to the stoichiometric or slightly rich mixtures where maximum temperature is reached. An exceptional behavior is observed for the $750 \mathrm{~K}$ case, where the most reactive mixture fraction is displaced to slightly lean regions. 

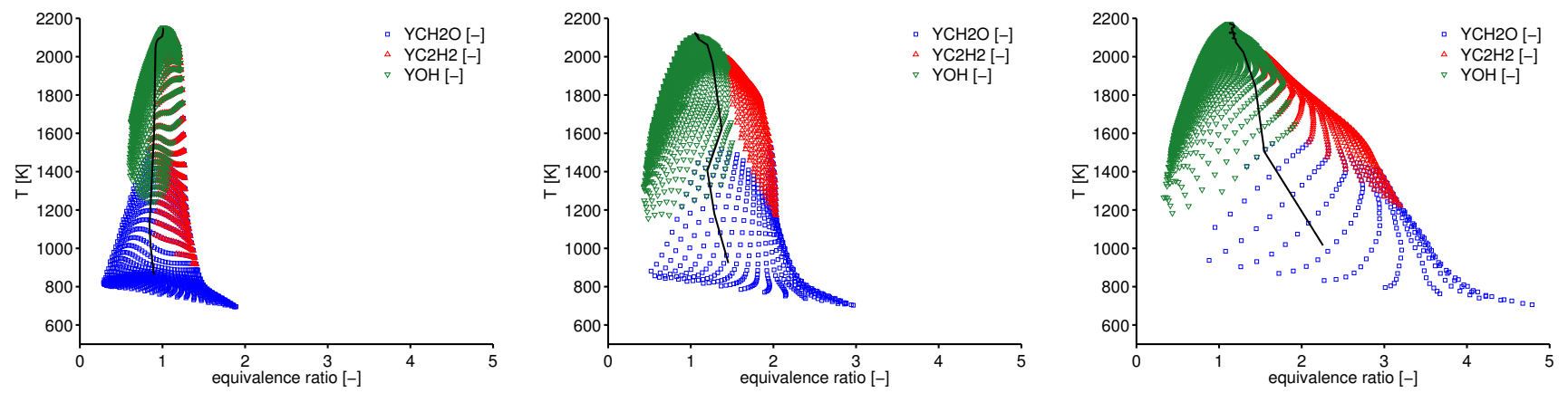

Figure 16: $\phi-T$ maps for $750 K$ (left), $800 K$ (center) and $900 K$ (right) with $X_{\mathrm{O}_{2}}=0.15$ and density $22.8 \mathrm{~kg} / \mathrm{m}^{3}$ for advanced instants. Species locations are included: $\mathrm{CH}_{2} \mathrm{O}$ (blue squares), $\mathrm{C}_{2} \mathrm{H}_{2}$ (red upward-pointing triangles) and $\mathrm{OH}$ (green downwardpointing triangles). The relation $\widetilde{T}_{\max }=\widetilde{T}_{\max }(\widetilde{\phi})$ during the ignition is plotted with solid black line. Scales are common for all cases.

Analogously, a similar comparison is discussed in the following for the oxygen parametric variation. Figure 17 shows in matrix format the species $\mathrm{CH}_{2} \mathrm{O}, \mathrm{C}_{2} \mathrm{H}_{2}$ and $\mathrm{OH}$ mass fractions fields for the oxygen parametric variation $\left(X_{O_{2}}=0.13,0.15\right.$ and 0.21$)$ with $T_{a m b}=900 \mathrm{~K}$ and $\rho=22.8 \mathrm{~kg} / \mathrm{m}^{3}$. Advanced instants with a similar penetration have been selected and quasisteady regime is ensured in the near-nozzle region. As previously, only simulated cases are included to carry out a quantitative comparison.
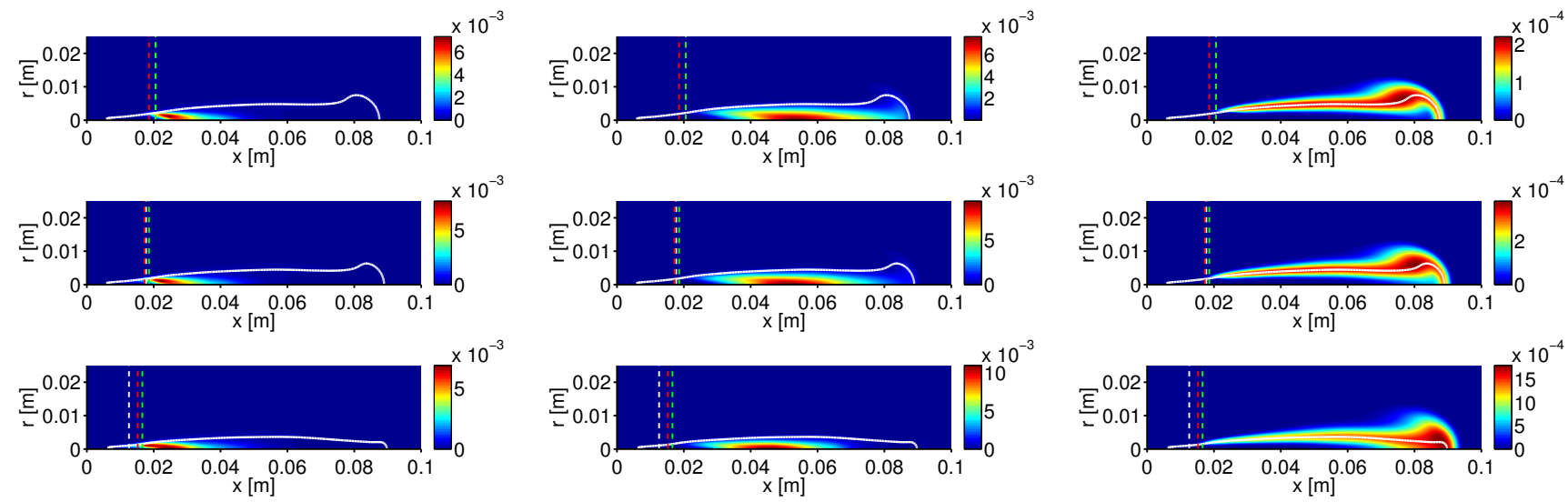

Figure 17: Species mass fractions fields of $\mathrm{CH}_{2} \mathrm{O}$ (left), $\mathrm{C}_{2} \mathrm{H}_{2}$ (center) and $\mathrm{OH}$ (right) for $\mathrm{X}_{\mathrm{O}_{2}}=0.13$ (top), 0.15 (middle) and 0.21 (bottom) with $T_{a m b}=900 \mathrm{~K}$ and density $22.8 \mathrm{~kg} / \mathrm{m}^{3}$ in matrix format. LOL values are included with dashed lines: experimental (white), $2 \%{\widetilde{Y_{O H}}}^{\max }$ (red) and $14 \% \widetilde{Y_{O H}}{ }^{\max }$ (green). Additionally, the stoichiometric line is shown (solid white).

The higher reactivity resulting from increasing the oxygen concentration displaces upstream the fields that reached the quasi-steady regime. There is a slight increase of soot precursors when increasing oxygen concentration as reflected by the $\mathrm{C}_{2} \mathrm{H}_{2}$ peak value. Additionally, there is a significant rise of the $O H$ maximum value when passing from $X_{O_{2}}=0.15$ to 0.21 .

The variation in the oxygen concentration changes the stoichiometric value of the mixture and consequently this has an effect in the zone, specially in the radial direction, where species are 
found due to the fact that stoichiometric contour line encloses the region where combustion takes place. As a consequence, $O H$ disappears on the axis when decreasing oxygen concentration.

The $\phi-T$ maps shown in figure 18 provide a complementary description of the combustion process for the oxygen parametric variation. Again only points with $Y_{i}>0.3 \cdot Y_{i}^{\max }$ are shown for species $\mathrm{CH}_{2} \mathrm{O}, \mathrm{C}_{2} \mathrm{H}_{2}$ and $\mathrm{OH}$. The region of influence of each species is preserved when varying the oxygen concentration in relative terms. The different species are approximately observed in the same equivalence ratio interval mainly changing the temperature range for the distinct cases.

With regards to the relation $\widetilde{T}_{\text {max }}=\widetilde{T}_{\text {max }}(\widetilde{\phi})$, the curve is similar in all the cases starting the ignition in rich mixtures $(\widetilde{\phi}>2)$, since it is the region with the most suitable combination in terms of mixture fraction variance and stoichiometric scalar dissipation rate as discussed in the previous subsection, and it subsequently displaces towards leaner mixtures. Finally, the dependence exhibited by the maximum temperature reached during the whole combustion process with the change in oxygen concentration is clearly reproduced by the model as seen in these maps.
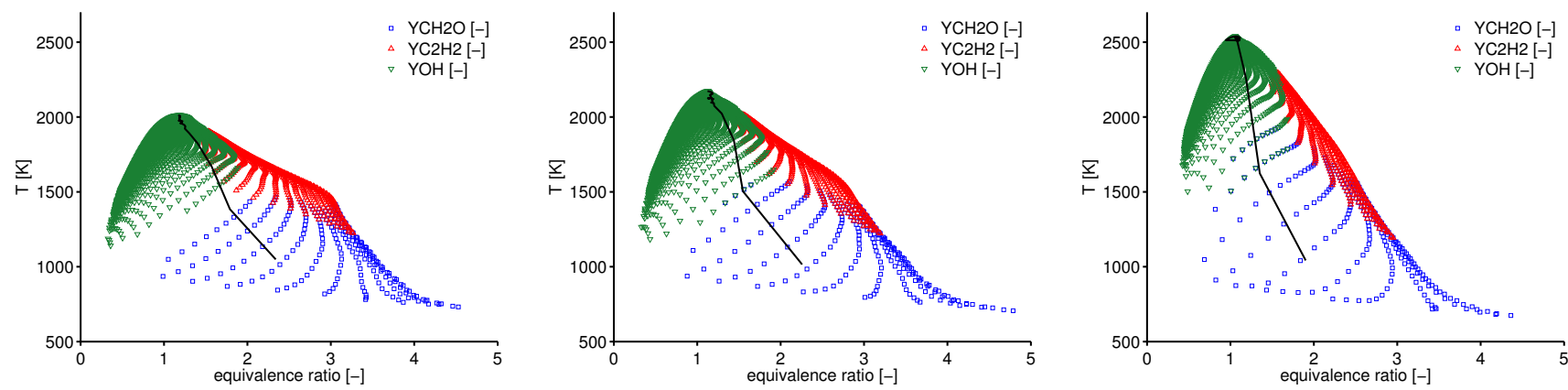

Figure 18: $\phi-T$ maps for $X_{O_{2}}=0.13$ (left), 0.15 (center) and 0.21 (right) with $T_{a m b}=900 K$ and density $22.8 \mathrm{~kg} / \mathrm{m}^{3}$ for advanced instants. Species locations are included: $\mathrm{CH}_{2} \mathrm{O}$ (blue squares), $\mathrm{C}_{2} \mathrm{H}_{2}$ (red upward-pointing triangles) and $\mathrm{OH}$ (green downward-pointing triangles). The relation $\widetilde{T}_{\max }=\widetilde{T}_{\max }(\widetilde{\phi})$ during the ignition is plotted with solid black line. Scales are common for all cases.

\section{Conclusions}

In this work, the spray A laboratory configuration has been modeled combining a discrete droplet (DDM) approach for the spray simulation with an unsteady flamelet combustion model (USFM), that includes the additional approximated diffusion flamelet (ADF) simplification, and accounting for the turbulence-chemistry interaction (TCI) by means of presumed probability density functions (pdf). This combustion model was selected because it accounts for the 
TCI with noticeable low computational cost becoming suitable for diesel engine calculations where boundary conditions span over wide ranges. A setup of the model for the inert and reactive nominal cases was first performed comparing results with those measured at different institutions in terms of penetration and mixture fraction and velocity fields. Although reactive vapor penetration was slightly overestimated results are on the state-of-the-art and then suitable for performing further analysis. Additionally, the constant of the algebraic model of the Favre averaged scalar dissipation rate was calibrated to a value of $C_{\chi}=2$ by comparing modeling and experimental rms mixture fraction fields.

The conclusions related to combustion global descriptors (ID and LOL) are summarized in the following points:

- The model correctly describes the trends followed by both ID and LOL parameters. For the LOL several criteria were compared in order to clear up the impact of the LOL definition based on values that trace the low or the high temperature reaction zones. According to the results the criterion based on the $14 \% \widetilde{Y_{O H}}$ max provides the most reasonable estimation. Nevertheless, some discrepancies were revealed between experimental and modeling results, partially due to the not equivalent definitions used in both cases, which resulted in an overestimation of the ID and a lack of sensitivity of the LOL for the oxygen parametric variation.

- A linear fit seems to exist between ID and LOL for low ID (and equivalently short LOL) confirming the intrinsic relation between the two parameters and the relationship between the LOL and the auto-ignition phenomenon. However, at high ID (and then long LOL) the relation between those variables is not so straightforward.

The description and analysis of the auto-ignition process lead to the following conclusions:

- A high mixture reactivity induces the ignition kernels to be radially displaced from the spray centerline and placed close to the head of the spray. Decreasing reactivity shifts the auto-ignition to take place still at the head of the spray but at closer positions to the centerline.

- Additionally, start of combustion is located at low $\widetilde{Z^{\prime \prime 2}}$ values as well as low $\overline{\chi_{s t}}$. An increase in reactivity without varying the spray mixing conditions results in a combustion onset at higher $\overline{\chi_{s t}}$ values. 
- Ignition kernels are first observed at higher fuel-air equivalence ratios when ambient temperature is increased.

With regards to the quasi-steady regime it is concluded that:

- A similar qualitative spatial morphology of the spray is provided by the model in comparison with the experimental results.

- Comparing different cases an increase in reactivity displaces upstream the regions where $\mathrm{CH}_{2} \mathrm{O}$ and $\mathrm{C}_{2} \mathrm{H}_{2}$ fields reach their maxima values in the quasi-steady regime although their relative distribution is hardly affected. $\mathrm{CH}_{2} \mathrm{O}$ zone of influence always precedes that of $\mathrm{C}_{2} \mathrm{H}_{2}$ since $\mathrm{CH}_{2} \mathrm{O}$ is an intermediate species during the auto-ignition close to the LOL and $\mathrm{C}_{2} \mathrm{H}_{2}$ is an intermediate species observed in zones with rich equivalence ratios and moderate-to-high temperatures.

- A noticeable fall of the $C_{2} H_{2}$ peak value is observed when passing to the $750 \mathrm{~K}, X_{\mathrm{O}_{2}}=$ $0.15, \rho=22.8 \mathrm{~kg} / \mathrm{m}^{3}$ case with regards to other temperature cases which points out to very reduced values of produced soot precursors. Likewise, $900 \mathrm{~K}, X_{\mathrm{O}_{2}}=0.21, \rho=22.8 \mathrm{~kg} / \mathrm{m}^{3}$ shows an important increase in $O H$ peak value compared to other oxygen cases.

Finally, this research work provides a detailed insight on the performance of the unsteady flamelet combustion models for reproducing the characteristics of igniting transient reacting sprays. Traditionally, these models have been applied to transport applications or gas turbine simulations, but in the last decade they are gaining interest for being also applied to simulate the mixing-controlled combustion process characteristic of compression ignition engines which are so relevant in industrial applications.

\section{$5 \quad$ Acknowledgments}

Authors acknowledge that this work was possible thanks to the Ayuda para la Formación de Profesorado Universitario (FPU 14/03278) belonging to the Subprogramas de Formación y de Movilidad del Ministerio de Educación, Cultura y Deporte from Spain. Also this study was partially funded by the Ministerio de Economía y Competitividad from Spain in the frame of the COMEFF (TRA2014-59483-R) national project. 


\section{References}

[1] F. Bazdidi-Tehrani, H. Zeinivand, Presumed pdf modeling of reactive two-phase flow in a three dimensional jet-stabilized model combustor, Energy Conversion and Management 51 (1) (2010) 225-234.

[2] M. Vujanović, Z. Petranović, W. Edelbauer, J. Baleta, N. Duić, Numerical modelling of diesel spray using the eulerian multiphase approach, Energy Conversion and Management 104 (2015) 160-169.

[3] L. Zhou, K. H. Luo, W. Qin, M. Jia, S. J. Shuai, Large eddy simulation of spray and combustion characteristics with realistic chemistry and high-order numerical scheme under diesel engine-like conditions, Energy Conversion and Management 93 (2015) 377-387.

[4] L. M. Pickett, G. Bruneaux, R. Payri, Engine combustion network, Sandia National Laboratories, Livermore, CA, http://www. ca. sandia. gov/ecn.

[5] L. M. Pickett, C. L. Genzale, G. Bruneaux, L. M. Malbec, L. Hermant, C. Christiansen, J. Schramm, Comparison of diesel spray combustion in different high-temperature, high-pressure facilities, SAE Int. J. Engines 3 (2) (2010) 156-181.

[6] M. Bardi, R. Payri, L. M. Malbec, G. Bruneaux, L. M. Pickett, J. Manin, T. Bazyn, C. L. Genzale, Engine combustion network: comparison of spray development, vaporization, and combustion in different combustion vessels, Atomization and Sprays 22 (10).

[7] R. Payri, J. P. Viera, Y. Pei, S. Som, Experimental and numerical study of lift-off length and ignition delay of a two-component diesel surrogate, Fuel 158 (2015) 957-967.

[8] M. Bolla, T. Gudmundsson, Y. M. Wright, K. Boulouchos, Simulations of diesel sprays using the conditional moment closure model, SAE International Journal of Engines 6 (2013-01-1618) (2013) 1249-1261.

[9] Y. Pei, E. R. Hawkes, S. Kook, G. M. Goldin, T. Lu, Modelling n-dodecane spray and combustion with the transported probability density function method, Combustion and Flame 162 (5) (2015) 2006-2019.

[10] S. Bhattacharjee, D. C. Haworth, Simulations of transient n-heptane and n-dodecane spray flames under engine-relevant conditions using a transported pdf method, Combustion and Flame 160 (10) (2013) 20832102.

[11] G. D'Errico, T. Lucchini, F. Contino, M. Jangi, X. S. Bai, Comparison of well-mixed and multiple representative interactive flamelet approaches for diesel spray combustion modelling, Combustion Theory and Modelling 18 (1) (2014) 65-88.

[12] Y. Pei, E. R. Hawkes, M. Bolla, S. Kook, G. M. Goldin, Y. Yang, S. B. Pope, S. Som, An analysis of the structure of an n-dodecane spray flame using TPDF modelling, Combustion and Flame 168 (2016) 420-435.

[13] S. A. Skeen, J. Manin, L. M. Pickett, Simultaneous formaldehyde PLIF and high-speed schlieren imaging for ignition visualization in high-pressure spray flames, Proceedings of the Combustion Institute 35 (3) (2015) 3167-3174.

[14] J. Benajes, R. Payri, M. Bardi, P. Martí-Aldaraví, Experimental characterization of diesel ignition and lift-off length using a single-hole ECN injector, Applied Thermal Engineering 58 (1) (2013) 554-563.

[15] R. Payri, J. M. García-Oliver, T. Xuan, M. Bardi, A study on diesel spray tip penetration and radial expansion under reacting conditions, Applied Thermal Engineering 90 (2015) 619-629.

[16] V. Knop, J.-B. Michel, O. Colin, On the use of a tabulation approach to model auto-ignition during flame propagation in SI engines, Applied Energy 88 (12) (2011) 4968-4979.

[17] S. Gövert, D. Mira, J. B. Kok, M. Vázquez, G. Houzeaux, Turbulent combustion modelling of a confined premixed jet flame including heat loss effects using tabulated chemistry, Applied Energy 156 (2015) 804815.

[18] A. Tyliszczak, A. Boguslawski, D. Nowak, Numerical simulations of combustion process in a gas turbine with a single and multi-point fuel injection system, Applied Energy 174 (2016) 153-165.

[19] A. C. Benim, S. Iqbal, W. Meier, F. Joos, A. Wiedermann, Numerical investigation of turbulent swirling flames with validation in a gas turbine model combustor, Applied Thermal Engineering 110 (2017) $202-212$.

[20] H. Barths, C. Hasse, G. Bikas, N. Peters, Simulation of combustion in direct injection diesel engines using a eulerian particle flamelet model, Proceedings of the Combustion Institute 28 (1) (2000) 1161-1168. 
[21] I. Dhuchakallaya, P. Rattanadecho, P. Watkins, Auto-ignition and combustion of diesel spray using unsteady laminar flamelet model, Applied Thermal Engineering 52 (2) (2013) 420-427.

[22] J. B. Michel, O. Colin, D. Veynante, Modeling ignition and chemical structure of partially premixed turbulent flames using tabulated chemistry, Combustion and Flame 152 (1) (2008) 80-99.

[23] J. B. Michel, O. Colin, D. Veynante, Comparison of differing formulations of the PCM model by their application to the simulation of an auto-igniting H2/air jet, Flow, Turbulence and Combustion 83 (1) (2009) 33-60.

[24] J. B. Michel, O. Colin, C. Angelberger, D. Veynante, Using the tabulated diffusion flamelet model ADFPCM to simulate a lifted methane-air jet flame, Combustion and Flame 156 (7) (2009) 1318-1331.

[25] J. Tillou, J. B. Michel, C. Angelberger, C. Bekdemir, D. Veynante, Large-eddy simulation of diesel spray combustion with exhaust gas recirculation, Oil \& Gas Science and Technology-Revue d'IFP Energies nouvelles 69 (1) (2014) 155-165.

[26] J. Tillou, J. B. Michel, C. Angelberger, D. Veynante, Assessing LES models based on tabulated chemistry for the simulation of diesel spray combustion, Combustion and Flame 161 (2) (2014) 525-540.

[27] J. M. Desantes, J. M. Garcia-Oliver, J. M. Pastor, A. Pandal, A comparison of diesel sprays CFD modeling approaches: DDM versus $\sigma$-Y eulerian atomization model, Atomization and Sprays 26 (7).

[28] S. B. Pope, An explanation of the turbulent round-jet/plane-jet anomaly, AIAA journal 16 (3) (1978) 279-281.

[29] R. Novella, A. García, J. M. Pastor, V. Domenech, The role of detailed chemical kinetics on CFD diesel spray ignition and combustion modelling, Mathematical and Computer Modelling 54 (7) (2011) 1706-1719.

[30] K. Narayanaswamy, P. Pepiot, H. Pitsch, A chemical mechanism for low to high temperature oxidation of n-dodecane as a component of transportation fuel surrogates, Combustion and Flame 161 (4) (2014) $866-884$.

[31] N. Peters, Turbulent combustion, Cambridge University Press, 2000.

[32] T. Poinsot, D. Veynante, Theoretical and numerical combustion, RT Edwards Inc., 2005.

[33] J. M. Desantes, R. Novella, J. M. Pastor, E. J. Pérez-Sánchez, Analysis of the approximated diffusion flamelet approach using fuels with different chemical complexity, in: Mathematical Modelling in Engineering \& Human Behaviour 2014. 16th Edition of the Mathematical Modelling Conference Series at the Institute for Multidisciplinary Mathematics, Valencia, Spain, 2014, pp. 228-233.

[34] C. Pera, O. Colin, S. Jay, Development of a FPI detailed chemistry tabulation methodology for internal combustion engines, Oil \& Gas Science and Technology-Revue de l'IFP 64 (3) (2009) 243-258.

[35] J.-B. Michel, O. Colin, A tabulated diffusion flame model applied to diesel engine simulations, International Journal of Engine Research (2013) 1468087413488590.

[36] B. Naud, R. Novella, J. M. Pastor, J. F. Winklinger, RANS modelling of a lifted H2/N2 flame using an unsteady flamelet progress variable approach with presumed PDF, Combustion and Flame 162 (4) (2015) 893-906.

[37] J. F. Winklinger, Implementation of a combustion model based on the flamelet concept and its application to turbulent reactive sprays, Ph.D. thesis, Universitat Politècnica de València (2015).

[38] CMT - Motores Térmicos, Universitat Politècnica de València, Spain, http://www.cmt.upv.es/ECN03.aspx.

[39] L. M. Pickett, J. Manin, C. L. Genzale, D. L. Siebers, M. P. B. Musculus, C. A. Idicheria, Relationship between diesel fuel spray vapor penetration/dispersion and local fuel mixture fraction, SAE International Journal of Engines 4 (2011-01-0686) (2011) 764-799.

[40] M. Meijer, L. M. Malbec, G. Bruneaux, L. M. T. Somers, Engine combustion network: spray A basic measurements and advanced diagnostics, in: 12th Triennial International Conference on Liquid Atomization and Spray Systems (ICLASS 2012), Heidelberg, Germany, September, 2012, pp. 2-6.

[41] W. E. Eagle, M. P. B. Musculus, L. M. C. Malbec, G. Bruneaux, Measuring transient entrainment rates of a confined vaporizing diesel jet, in: ILASS Americas 26th Annual Conference on Liquid Atomization and Spray Systems, Portland, OR, 2014. 
[42] E. R. Hawkes, ECN2: ignition and lift-off session, in: Engine Combustion Network Workshop Two, Germany, 2012.

[43] P. Kundu, Y. Pei, M. Wang, R. Mandhapati, S. Som, Evaluation of turbulence-chemistry interaction under diesel engine conditions with multi-flamelet RIF model, Atomization and Sprays 24 (9).

[44] C. Bajaj, M. Ameen, J. Abraham, Evaluation of an unsteady flamelet progress variable model for autoignition and flame lift-off in diesel jets, Combustion Science and Technology 185 (3) (2013) 454-472.

[45] L. M. Pickett, D. L. Siebers, C. A. Idicheria, Relationship between ignition processes and the lift-off length of diesel fuel jets, Tech. rep., SAE technical paper (2005).

[46] Y. Pei, M. J. Davis, L. M. Pickett, S. Som, Engine combustion network (ECN): global sensitivity analysis of spray a for different combustion vessels, Combustion and Flame 162 (6) (2015) 2337-2347.

[47] C. S. Yoo, E. S. Richardson, R. Sankaran, J. H. Chen, A DNS study on the stabilization mechanism of a turbulent lifted ethylene jet flame in highly-heated coflow, Proceedings of the Combustion Institute 33 (1) (2011) 1619-1627.

[48] C. Gong, M. Jangi, X.-S. Bai, Large eddy simulation of n-dodecane spray combustion in a high pressure combustion vessel, Applied Energy 136 (2014) 373-381.

[49] M. Epaminondas, Ignition of turbulent non-premixed flames, Progress in Energy and Combustion Science 35 (1) (2009) 57-97.

[50] N. Maes, M. Meijer, N. Dam, B. Somers, H. B. Toda, G. Bruneaux, S. A. Skeen, L. M. Pickett, J. Manin, Characterization of spray A flame structure for parametric variations in ECN constant-volume vessels using chemiluminescence and laser-induced fluorescence, Combustion and Flame 174 (2016) 138-151.

[51] L. M. Pickett, D. L. Siebers, Soot in diesel fuel jets: effects of ambient temperature, ambient density, and injection pressure, Combustion and Flame 138 (1) (2004) 114-135. 